\title{
Asymmetric unemployment fluctuations and monetary policy trade-offs
}

\author{
Antoine Lepetit* \\ First version: June 2013. This version: October 2014
}

\begin{abstract}
I show that a trade-off between inflation volatility and average unemployment arises in a New Keynesian model with search and matching frictions in the labor market. In this environment, unemployment rises more and faster in a recession than it decreases in an expansion. A monetary authority focused solely on stabilizing inflation exacerbates labor market volatility and leads to higher average unemployment. When the model is calibrated to the U.S. economy, the welfare gains of adopting the optimal policy rather than a policy of price stability are found to be substantial. Moreover, the bulk of those welfare gains arises from the increase in mean employment achieved by the Ramsey policymaker. This result points to the importance of the asymmetric nature of unemployment fluctuations in shaping monetary policy trade-offs. The introduction of imperfect unemployment insurance does not change the results in a significant way.
\end{abstract}

Keywords: Optimal monetary policy; matching frictions

JEL Codes: E52; E24

${ }^{*}$ Paris I and Paris School of Economics - 106-112 Boulevard de l'Hôpital, 75013 Paris antoine.lepetit@live.fr. I would like to thank Florin Bilbiie, Nicolas Dromel, Francesco Furlanetto, Jesper Lindé, Pascal Michaillat, Espen Moen, Julien Prat, Jordan Roulleau-Pasdeloup as well as seminar participants at CREST and Norges Bank for useful comments. An earlier version of this paper circulated under the title "Reassessing the rationale for price stability in the presence of matching frictions". 


\section{Introduction}

How much weight should a central bank place on employment when conducting monetary policy? This question has received renewed interest among policy circles during the recent recession as unemployment rates have soared to unprecedented levels in many countries. However, at least officially, a certain number of central banks around the world have a single inflation goal and put very little emphasis on the stabilization of real variables such as unemployment. This practice has some grounding in economic theory. In the last years, a fruitful literature has sought to integrate the modern search and matching theory of unemployment in the New Keynesian model in order to study the joint dynamics of inflation and unemployment. In such a framework, a meaningful tradeoff between inflation and unemployment stabilization arises as a policymaker can use inflation to correct for an inefficient level of labor market activity. However, as emphasized by Ravenna and Walsh (2012), in several calibrated versions of these models, the level of welfare obtained under the optimal policy is very close to the one attained under a policy of price stability. This finding is surprising insofar as several papers (Hairault et al. 2010, Jung and Kuester 2011, PetroskyNadeau and Zhang 2013) have showed that unemployment fluctuations can be very costly in the presence of matching frictions. This paper evaluates whether this rationale for price stability is still valid in an environment that captures the substantial business cycle costs documented in these studies.

I use a standard model in which search and matching frictions in the labor market prevent job seekers from finding a job and vacancies from being filled immediately. This gives rise to equilibrium unemployment. Wholesale firms use labor as the only input in the production process and sell their goods to monopolistic retail firms, which face quadratic price adjustement costs. This last feature generates a Phillips Curve that relates the markup to inflation. In such a setting, shifts in firms' real revenues due to variations in labor productivity lead to approximately symmetric reactions in the job finding rate. However, these fluctuations in the job finding rate have an asymmetric effect on employment. In an expansion, the positive impact on employment of an increase in the job finding rate is dampened by the decrease in the size of the pool of job seekers. In a recession, the negative impact on employment of the decrease in the job finding rate is amplified by the increase in the size of the pool of job seekers. Thus, in the presence of matching frictions, mean unemployment will tend to increase with aggregate fluctuations. For this effect to be significant, one needs a model that generates a substantial amplification of shocks. This motivates the introduction of real wage rigidity in my framework. In this environment, the central bank may try to use inflation to influence markups, with the goal of affecting job creation and dampening fluctuations in the job-finding rate. By doing so, it can have an impact on average unemployment. The objective of this paper is to study how the presence of this costly asymmetry in unemployment fluctuations shapes the optimal conduct of monetary policy. 
Results are as follows. The adoption of different monetary policy rules may lead to very different outcomes in terms of average unemployment. When the monetary authority responds to both inflation and output growth, the unemployment losses arising from business cycles amount to 0.2 percentage points. However, under a policy of price stability, these losses double to 0.44 percentage points. The intuition for this result is as follows. Under the first rule, the monetary authority engineers procyclical markups in response to technology shocks. This limits the variations in firms' real revenues and gives them less incentives to expand or cut back on job creation. As a result, unemployed workers face more stable employment prospects. Consistently with the mechanism outlined in the preceding paragraph, the smaller fluctuations in the job finding rate lead to lower mean unemployment losses. Under a policy of price stability, markups are constant over the business cycle and real revenues and job creation are accordingly more volatile. This results in larger fluctuations in the job-finding rate and higher average unemployment. Thus the central bank faces a trade-off between inflation volatility and average unemployment. By using inflation to influence markups, it can dampen labor market volatility and limit unemployment losses.

The design of optimal monetary policy in this paper follows the Ramsey approach, which has been applied in a wide range of New-Keynesian models (for example King and Wolman 1999, Khan et al. 2003, Schmitt-Grohe and Uribe 2006, Bilbiie et al. 2014). By deviating markedly from price stability, the Ramsey planner is able to limit both labor market volatility and unemployment losses. Average unemployment is only 0.13 percentage points higher than in steady-state. Moreover, the welfare gains of adopting the optimal policy rather than a policy of price stability are quite significant. The bulk of the welfare gains are due to an increase in mean consumption. In turn, it can be shown that this increase in average consumption mostly follows from the increase in average employment achieved by the Ramsey policymaker. Thus, these results point to the crucial role played by the asymmetric nature of employment flucuations in shaping monetary policy tradeoffs. In the absence of such asymmetry, monetary policy would be unable to influence mean consumption, and the welfare gains of adopting the optimal policy would accordingly be smaller. Additionally, a parameter, the flow value of unemployment, is key in influencing welfare outcomes. Because the wage process is exogenous, the value of this parameter barely affects the cyclical properties of the model. However it does determine how given mean unemployment losses translate to consumption losses. The lower it is, the more costly is a decrease in average employment and the more beneficial it becomes to adopt the optimal policy rather than a policy of price stability. Finally, I find that introducing imperfect unemployment insurance in this framework does not alter the result in quantitatively significant way.

These results contribute to a large literature on the design of optimal monetary policy by showing that the asymmetric nature of unemployment fluctuations in the presence of matching frictions can justify quantitatively relevant deviations 
from price stability. In the standard New Keynesian model, price stability is the optimal policy as it implies the stabilization of the welfare-relevant output gap. This conclusion is robust to the inclusion of other features such as financial frictions and frictions due to the openness of the economy, as emphasized in Walsh (2014). A large literature has focused on the specific case of labor market frictions. Faia (2009) shows that a trade-off between inflation and unemployment stabilization arises in the presence of search and matching frictions as a central bank can use inflation to correct for an inefficient level of labor market activity. Faia (2008) found that a small response to unemployment alongside a strong response to inflation can implement the optimal policy. However, in her model, the gains of adopting this policy rather than a policy of price stability are very small. Thomas (2008) also found that when real wages are rigid, the monetary authority should focus on stabilizing inflation. In Blanchard and Galís (2010) model, the introduction of a direct utility cost of employment fluctuations can justify optimal deviations from price stability. Ravenna and Walsh (2012) summarize all those contributions by showing that inefficiencies due to matching frictions can be large but that the incentive to deviate from price stability is nonetheless small. This discrepancy ${ }^{1}$ between the results of this paper and those of the literature is mainly due to two elements. In order to capture the large costs due to asymmetric unemployment fluctuations, it is necessary to use both non-linear solution methods and a model with a strong internal propagation mechanism. An extensive review of the literature in section 5 provides further explanation.

The paper is organized as follows. Section 2 develops the model. Section 3 undertakes a comparative steady-states exercise to understand the origin of the asymmetry in unemployment fluctuations. Section 4 calibrates the model and shows that the monetary authority faces a trade-off between inflation volatility and average unemployment. Section 5 derives the Ramsey optimal monetary policy, provides a welfare ranking of alternative policies and compares the results of the paper with those of the existing literature. Section 6 evaluates whether the introduction of imperfect unemployment insurance calls for more unemployment stabilization. Section 7 concludes.

\section{A New Keynesian model with search and match- ing frictions}

This section develops a model with sticky prices in which monetary policy has a meaningful role to play. It departs from the standard New Keynesian model in several ways. The labor market is not perfectly competitive but is characterized by search and matching frictions. The surplus of a match is divided between

\footnotetext{
${ }^{1}$ The results are actually entirely consistent with Ravenna and Walsh's observation that the gains from deviating from price stability are larger in economies with more volatile labor flows. The analysis carrried out in this paper provides an explanation for this observation.
} 
the worker and the firm according to an exogenous rule that determines the real wage. The economy consists of two sectors of production. Wholesale firms operate in perfectly competitive markets. They use labor as the sole input in the production process and have to post vacancies in order to match with workers. Their output is sold to monopolistically competitive retail firms which transform the homogeneous goods one for one into differentiated goods and must pay a quadratic adjustment cost to change their prices.

\subsection{Model}

\subsubsection{Labor market}

The size of the labor force is normalized to unity. Workers and firms need to match in order to become productive. The number of matches in period $t$ is given by a Cobb-Douglas matching function $m_{t}=\mu s_{t}^{\alpha} v_{t}^{1-\alpha}, s_{t}$ being the number of job-seekers and $v_{t}$ the number of vacancies posted by firms. The parameter $\mu$ reflects the efficiency of the matching process and $\alpha \in(0,1)$ is the elasticity of the matching function with respect to unemployment. Define $\theta_{t}=\frac{v_{t}}{s_{t}}$ as labor market tightness. The probability $q_{t}$ for a firm to fill a vacancy and the probability $p_{t}$ for a worker to find a job are, respectively, $q_{t}=\frac{m_{t}}{v_{t}}=$ $\mu \theta_{t}^{-\alpha}$ and $p_{t}=\frac{m_{t}}{s_{t}}=\mu \theta_{t}^{1-\alpha}$. At the beginning of each period, a fraction $\rho$ of existing employment relationships is exogenously destroyed. Those $\rho N_{t-1}$ newly separated workers and the $1-N_{t-1}$ workers unemployed in the previous period form the pool of job seekers $s_{t}=1-(1-\rho) N_{t-1}$. Job seekers have a probability $p_{t}$ of finding a job within the period. The law of motion of employment $N_{t}$ is accordingly given by

$$
N_{t}=(1-\rho) N_{t-1}+p_{t}\left(1-(1-\rho) N_{t-1}\right)
$$

The number of unemployed workers in period $t$ is $u_{t}=1-N_{t}$.

\subsubsection{Households}

Each household is thought of as a large extended family which insures its members against consumption risk. The household makes the consumption and savings decisions. It has expected utility

$$
E_{0} \sum_{t=0}^{\infty} \beta^{t} \frac{C_{t}^{1-\sigma}}{1-\sigma}
$$

where $C_{t}$ is consumption of each household's member. Households supply hours $h$ inelastically ( $h$ is normalized to 1 ). Total labour income is given by $w_{t} N_{t}$ and the value of home production of unemployed household members is $b$. Households receive profits $\Pi_{t}^{r}$ from retail firms and invest in risk-free bonds that 
promise a unit of currency tomorrow and cost $\left(1+I_{t}\right)^{-1}$ today. They face the following per period budget constraint

$$
P_{t} C_{t}+\left(1+I_{t}\right)^{-1} B_{t+1}=P_{t}\left[w_{t} N_{t}+b\left(1-N_{t}\right)\right]+B_{t}+P_{t} \Pi_{t}^{r}
$$

Consumption of market goods is given by $C_{t}^{m}=C_{t}-b\left(1-N_{t}\right) . \quad C_{t}^{m} \equiv$ $\int_{0}^{1}\left[C_{t}^{m}(j)^{\frac{\varepsilon-1}{\varepsilon}} d j\right]^{\frac{\varepsilon}{\varepsilon-1}}$ is a Dixit-Stiglitz aggregator of the different varieties of goods produced by the retail sector and $\varepsilon$ is the elasticity of substitution between the different varieties. The optimal allocation of income on each variety is given by $C_{t}^{m}(j)=\left[\frac{P_{t}(j)}{P_{t}}\right]^{-\varepsilon} C_{t}^{m}$, where $P_{t}=\left[\int_{0}^{1} P_{t}(j)^{\frac{\varepsilon-1}{\varepsilon}} d j\right]^{\varepsilon /(1-\varepsilon)}$ is the price index. Households choose consumption and bonds holding so as to maximize (2) subject to (3). The household's optimal consumption path is governed by a standard Euler equation

$$
\beta E_{t} \frac{1+I_{t}}{\Pi_{t+1}}\left(\frac{C_{t+1}}{C_{t}}\right)^{-\sigma}=1
$$

\subsubsection{Wholesale firms}

A measure one of wholesale firms, indexed by $i$, produces according to the following technology

$$
Y_{i t}^{w}=Z_{t} N_{i t}
$$

where $Z_{t}$ is a common, aggregate productivity disturbance. Wholesale firms sell their output in a competitive market at a price $P_{t}^{w}$. Posting a vacancy comes at a cost $\kappa$. Firm $i$ chooses its level of employment $N_{i t}$ and the number of vacancies $v_{i t}$ in order to maximize the expected sum of its discounted profits

$$
E_{0} \sum_{t=0}^{\infty} \beta^{t} \frac{C_{t}^{-\sigma}}{C_{0}^{-\sigma}}\left[\frac{P_{t}^{w}}{P_{t}} Y_{i t}^{w}-\kappa v_{i t}-w_{t} N_{i t}\right]
$$

subject to its perceived law of evolution of employment $N_{i t}=(1-\rho) N_{i t-1}+$ $v_{i t} q\left(\theta_{t}\right)$ and taking the wage schedule as given. Profits are equal to real revenues minus vacancy posting costs and wage payments. They are discounted using the household's discount factor $\beta^{t} \frac{C_{t}^{-\sigma}}{C_{0}^{-\sigma}}$ since households ultimately own firms. In equilibrium all firms will post the same number of vacancies and employ the same number of workers. I therefore drop individual firm subscripts $i$. After rearranging the first-order conditions, the following job creation equation obtains

$$
\frac{\kappa}{q\left(\theta_{t}\right)}=\frac{Z_{t}}{\mu_{t}}-w_{t}+E_{t} \beta_{t+1}(1-\rho) \frac{\kappa}{q\left(\theta_{t+1}\right)}
$$


where $\beta_{t+1}=\beta\left(\frac{C_{t+1}}{C_{t}}\right)^{-\sigma}$ is the stochastic discount factor of households between periods $t$ and $t+1$ and $\mu_{t}=\frac{P_{t}}{P_{t}^{w}}$ is the markup of retail over wholesale prices. This equation is an arbitrage condition for the posting of vacancies. It states that the cost of posting a vacancy, the deadweight cost $\kappa$ divided by the time it takes to fill the vacancy, must be equal to the expected discounted benefit of a filled vacancy. These benefits consist of the revenues from output net of wages and the future savings on vacancy posting costs.

\subsubsection{Retail firms}

There is a large number of retailers, indexed by $j$, which buy the goods produced by wholesale firms at a price $P_{t}^{w}$ and transform them one for one into differentiated goods. $P_{t}^{w}$ represents the nominal marginal cost of production for retailers. They face quadratic cost of adjusting prices $\Theta_{t}(j)=\frac{\phi^{p}}{2}\left(\frac{P_{t}(j)}{P_{t-1}(j)}-\Pi\right)^{2} Y_{t}$ which are measured in terms of aggregate output. Retail firms choose $P_{t}(j)$ in order to maximize

$$
E_{0} \sum_{t=0}^{\infty} \beta^{t} \frac{C_{t}^{-\sigma}}{C_{0}^{-\sigma}}\left[\frac{P_{t}(j)-P_{t}^{w}}{P_{t}} Y_{t}(j)-\Theta_{t}(j)\right]
$$

subject to the demand for each variety $Y_{t}(j)=\left(P_{t}(j) / P_{t}\right)^{-\epsilon} Y_{t}^{d}$ where $Y_{t}^{d}$ is aggregate demand for final goods. Noting that in the symmetric equilibrium $P_{t}(j)=P_{t}$ and using the notation $\Pi_{t}=\frac{P_{t}}{P_{t-1}}$, we obtain

$$
1-\epsilon+\frac{\varepsilon}{\mu_{t}}-\phi^{p} \Pi_{t}\left(\Pi_{t}-\Pi\right)+E_{t} \beta_{t+1} \phi^{p} \Pi_{t+1}\left(\Pi_{t+1}-\Pi\right) \frac{Z_{t+1} N_{t+1}}{Z_{t} N_{t}}=0
$$

This equation is a non-linear expectational Phillips Curve linking marginal cost and inflation. Because of the presence of sticky prices, inflation has an influence on markups. The higher the difference between today's and tomorrow's inflation, the lower is the inefficiency arising from monopolistic competition. Importantly, lower markups (and higher marginal costs) for retail firms imply higher relative prices for wholesale firms and greater benefits from a filled vacancy. Thus by engineering an increasing path for inflation, monetary policy can encourage firms to hire more workers and thereby reduce unemployment. It should also be noted that the stochastic discount factor, which is used by firms to discount the future benefits of a posted vacancy, is the inverse of the real interest rate. Thus, monetary policy can also influence labor market activity through this channel.

\subsubsection{Wage setting}

As first emphasized by Shimer (2005), the Mortensen-Pissarides model is unable to account for the volatility of labor market variables observed in U.S. data. In the case of Nash-bargained flexible wages, the wage is too sensitive 
to aggregate conditions and "eats" all the incentives of firms to adjust through the employment margin. The introduction of real wage rigidity helps mitigate this problem. I introduce wage rigidity in the form of the Blanchard and Galí (2010) wage schedule

$$
w_{t}=\omega Z_{t}^{\gamma}
$$

where $\gamma \in[0,1]$ is the elasticity of wages with respect to technology. When $\gamma<1$, the wage adjusts only partially to technology shocks. As emphasized by Hall (2005), search frictions create a bargaining set between employer and employee. Thus, any (sticky) wage that remains between the worker's and the employer's reservation wages is consistent with the private efficiency of employ-

ment relationships. I will check in the different simulations conducted in sections 4 and 5 that wages always lie in the bargaining set.

\subsubsection{Monetary policy and equilibrium}

It is assumed that monetary policy adjusts interest rates in response to movements in inflation and output growth according to the following rule

$$
\log \left(\frac{1+I_{t}}{1+I}\right)=\phi_{r} \log \left(\frac{1+I_{t-1}}{1+I}\right)+\left(1-\phi_{r}\right)\left(\phi_{\pi} \log \left(\Pi_{t}\right)+\phi_{\Delta y} \log \left(Y_{t} / Y_{t-1}\right)\right)
$$

The economy-wide resource constraint is obtained by aggregating the budget constraints of households. Final output and home production can be used for consumption or to cover the deadweight costs of changing prices and posting vacancies

$$
C_{t}=Z_{t} N_{t}\left(1-\frac{\phi^{p}}{2}\left(\Pi_{t}-\Pi\right)^{2}\right)+b\left(1-N_{t}\right)-\kappa v_{t}
$$

We can now define an equilibrium.

DEFInition: A competitive equilibrium is a set of plans $\left\{C_{t}, I_{t}, N_{t}, \mu_{t}, \theta_{t}, \pi_{t}, w_{t}\right\}$ satisfying equations (1), (4), (7),(8), (9), (10), and (11) given a specification for the exogenous process $\left\{Z_{t}\right\}$ and initial conditions $N_{-1}$ and $\theta_{-1}$.

Technology will be modeled as a first-order autoregressive process $Z_{t}-\bar{Z}=$ $\delta_{Z}\left(Z_{t-1}-\bar{Z}\right)+\varepsilon_{t}^{Z}$ where $0<\delta_{Z}<1$ and $\varepsilon_{t}^{Z} \backsim\left(0, \sigma_{\varepsilon^{Z}}^{2}\right)$ is a white noise innovation.

\section{Steady-state analysis: uncovering the asymme- try in unemployment fluctuations}

This section undertakes a comparative steady-states exercise in order to understand the origin of the asymmetry in unemployment fluctuations. I solve for the zero-inflation steady state equilibrium of the model. In that case, markups 
are constant and the equilibrium consists of three endogenous variables: labor market tightness, unemployment and consumption. In the following equations, steady-state variables are indicated by the absence of a time subscript. Equilibrium labor market tightness is given by the job creation equation

$$
\frac{\kappa}{q(\theta)}=\frac{1}{1-(1-\rho) \beta}\left(\frac{Z}{\mu}-\omega Z^{\gamma}\right)
$$

When $\alpha=0.5$, we have that $p(\theta)=\frac{\mu^{2}}{q(\theta)}$, hence the previous equation can be rewritten in the following way

$$
p=\frac{\mu^{2}}{\kappa(1-(1-\rho) \beta)}\left(\frac{Z}{\mu}-\omega Z^{\gamma}\right)
$$

Thus, the job finding rate $p$ is entirely determined by the level of productivity $Z$. In the $(u, p)$ plane of Figure 1, the job creation curve is a horizontal line. Now that we have obtained the job-finding rate, we can deduce the unemployment rate from the steady-state version of equation (1), $p=\frac{\rho(1-u)}{1-(1-\rho)(1-u)}$. This employment flow curve is decreasing and convex in the $(u, p)$ plane of Figure 1.

This figure shows that shifts in productivity lead to almost symmetric shifts in the job finding rate, but asymmetric shifts in unemployment. When $Z=1$, steady-state unemployment is equal to $6 \%$. When productivity increases by $2.5 \%$, steady-state unemployment decreases by $4 \%$. However, when productivity decreases by $2.5 \%$, steady-state unemployment increases dramatically and reaches $14.5 \%$. The intuition behind this result is simple. In an expansion, the impact on unemployment of an increase in the job-finding rate is dampened by the fact that the pool of job seekers is shrinking. In a recession, the impact on unemployment of a decrease in the job-finding rate is amplified by the fact that the pool of job seekers is expanding. In other words, in a search and matching model of the labor market, unemployment losses in recessions tend to be greater than unemployment gains in expansions. Unemployment fluctuations are asymmetric, and mean unemployment is higher in an economy with business cycles than in steady-state. Following Jung and Kuester (2011), we can obtain an analytical expression for $E\left(u_{t}\right)-u$, the extra unemployment brought about by business cycles. Assuming that all variables in the employment-flow equation (1) are covariance stationary, $E\left(u_{t}\right)-u$ is given by

$$
E\left(u_{t}\right)-u=-\frac{1-\rho}{\rho+(1-\rho) p}\left[\operatorname{cov}\left(p_{t}, u_{t-1}\right)+\left(\frac{\rho}{1-\rho}+E\left(u_{t}\right)\right)\left(E\left(p_{t}\right)-p\right)\right]
$$

The proof of this result is presented in Appendix 1. The covariance between the job-finding rate and the unemployment rate captures the asymmetry in 


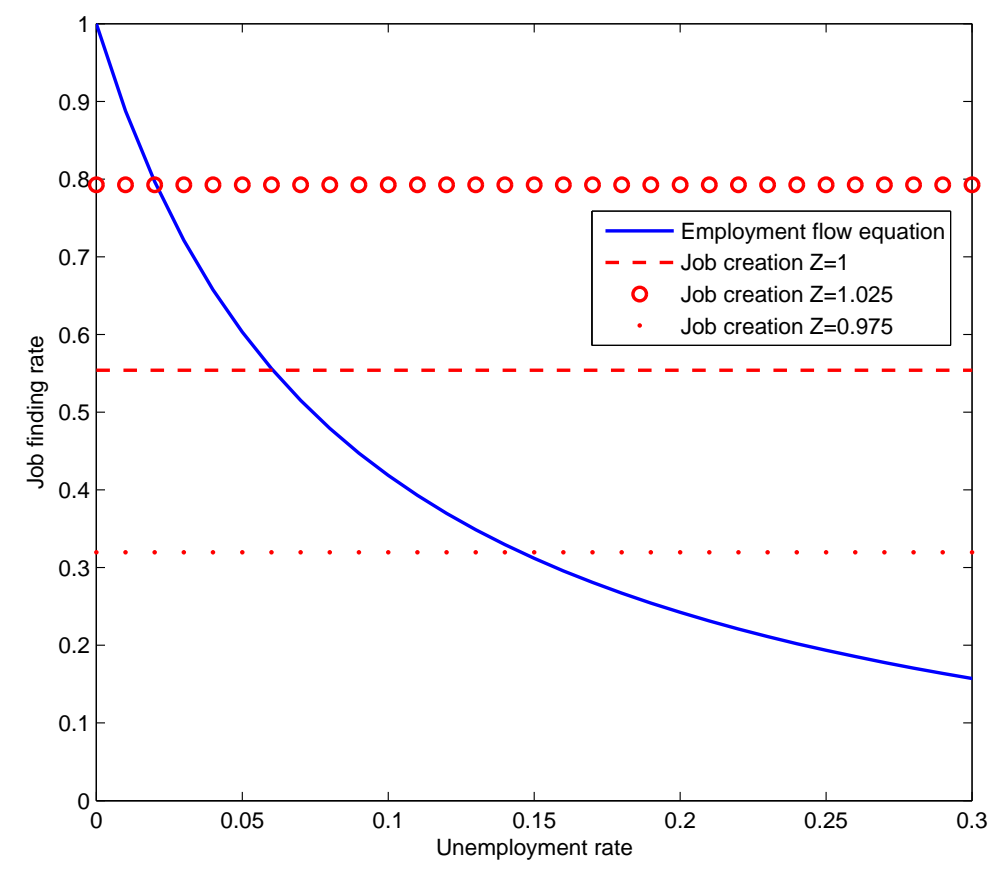

Figure 1: Steady-state equilibrium of the model. The solid blue line represents the steady-state version of the employment flow equation. The red, dashed line represents the steady-state version of the job creation equation for $Z=1$. The red, circled line represents the steady-state version of the job creation equation for $Z=1.025$. The red, pointed line represents the steady-state version of the job creation equation for $Z=0.975$. The calibration required to obtain the figure is detailed in section 4.1 .

unemployment fluctuations brought about by symmetric shifts in the job-finding rate. The second term $E\left(p_{t}\right)-p$ captures the extent to which fluctuations in the job-finding rate are asymmetric. In this comparative steady-states example, fluctuations in the job-finding rate are symmetric only if $\gamma=0$. Out of steadystate, fluctuations in the stochastic discount factor and markups will also drive a wedge between $E\left(p_{t}\right)$ and $p$. However, the following sections show that the bulk of the unemployment losses due to business cycles is accounted for by the negative covariance between the job-finding rate and the unemployment rate.

The analysis carried out so far suggests that the more volatile the job finding rate is, the larger is the asymmetry in unemployment fluctuations. Through its influence on firms' markups, monetary policy has the ability to influence job creation and labor market volatility. The next section explores in a quantitative 
manner how different monetary policy rules can lead to different outcomes in terms of mean unemployment.

\section{Monetary policy, labor market volatility and mean unemployment}

\subsection{Calibration and solution method}

I calibrate the model to U.S. data. I take one period to be a quarter. Table 1 gives a summary of the values of the parameters.

A few parameters are calibrated using conventional values. The discount factor is set to $\beta=0.99$, which yields an annual interest rate of $4 \%$. The elasticity of substitution between goods is $\varepsilon=6$, which corresponds to a steady-state markup of $20 \%$. I choose a coefficient of relative risk aversion $\sigma=1.5$. The price adjustment cost parameter $\phi^{p}$ is chosen according to the following logic. The linearized Phillips Curve of the model is observationally equivalent to the one derived under Calvo pricing, and structural estimates of New Keynesian models find an elasticity of inflation with respect to marginal cost $\omega$ of 0.5 (Lubik and Schorfheide 2004). In my model $\omega=\frac{\varepsilon-1}{\phi^{p}}$, which implies that $\phi^{p}=$ 10. Alternatively, assuming an average contract duration of 4 quarters, the coefficient $\omega$ under Calvo pricing would be equal to 0.0858 . This implies $\phi^{p}=60$. I choose an intermediate value $\phi^{p}=40$. This is also the value chosen by Krause and Lubik (2007).

Next, I calibrate the labor market parameters. I set the elasticity of matches with respect to unemployment at $\alpha=0.5$, within the range of plausible values proposed by Petrongolo and Pissarides (2001). I set the steady state values of unemployment and labor market tightness to their empirical counterparts. I use the seasonally-adjusted monthly unemployment rate constructed by the Bureau of Labor Statistics (BLS) from the Current Population Survey (CPS). Labor market tightness is computed as the ratio of a measure of the vacancy level to this measure of unemployment. The measure of the vacancy level is obtained by merging the vacancy data of the Conference Board help-wanted advertisement index for 1951-2001 and the seasonally-adjusted monthly vacancy level constructed by the BLS from JOLTS for 2001-2012. Over the period 1951-2012, the mean of the unemployment rate is $5.8 \%$ and the mean of labor market tightness is 0.61 . For practical purposes, my targets will be $6 \%$ and 0.6 respectively. The separation rate is set to 0.08 . These targets imply through the steady-state employment flow equation a quarterly job-finding probability of 0.56 , and through the definition of the job finding probability, a matching efficiency of 0.7181 . Silva and Toledo (2006) report that hiring costs amount to about $14 \%$ of quarterly employee compensation based on a study by the Saratoga Institute. Thus, the vacancy posting cost is assumed to be equal to $\kappa=0.14 q w$. I can then back out the steady-state value of the real wage from the 


\begin{tabular}{|c|c|c|}
\hline & Parameter/SS value & Justification \\
\hline \hline$\beta$ & 0.99 & Corresponds to an interest rate of $4 \%$ annually \\
\hline$\phi^{p}$ & 40 & Intermediate value \\
\hline$\sigma$ & 1.5 & Convential value \\
\hline$\varepsilon$ & 6 & Steady state markup of $20 \%$ \\
\hline$\alpha$ & 0.5 & Petrongolo and Pissarides (2001) \\
\hline$\rho$ & 0.08 & Conventional value \\
\hline$u$ & $6 \%$ & Mean over the period 1951-2012 \\
\hline$\theta$ & 0.6 & Hiring costs $=14 \%$ of quarterly compensation \\
\hline$\kappa$ & 0.1068 & Benhabib et al. (1991), Aguiar et al. (2013) \\
\hline$b$ & 0.4 & Haefke et al. (2013) \\
\hline$\gamma$ & 0.8 & Matches U.S. standard deviation and persistence \\
\hline$\zeta$ & 0.9 & of labor productivity \\
\hline$\sigma_{\varepsilon} z$ & 0.009 & Galí and Rabanal (2005) \\
\hline$\phi_{r}$ & 0.69 & Galí and Rabanal (2005) \\
\hline$\phi_{\pi}$ & 1.35 & Galí and Rabanal (2005) \\
\hline$\phi_{\Delta y}$ & 0.26 & \\
\hline
\end{tabular}

Table 1: Calibrated parameters

job creation equation. I obtain $\omega=\frac{\frac{1}{\mu}}{1+0.14(1-\beta(1-\rho))}=0.8231$ and $\kappa=0.1068$. Pissarides (2009) and Haefke et al. (2013) emphasize that job creation depends on the expected net present value of wages over the entire duration of the newly created jobs. Since wages in existing matches are known to be unresponsive to changes in aggregate conditions, it is the elasticity of the wages of new hires with respect to technology that matters for job creation. Following estimates in Haefke et al. (2013), I set this elasticity $\gamma$ to 0.8. Benhabib et al. (1991) indicate that estimates of home-produced output relative to measured gross national product are in the range of 20-50 percent. In a more recent paper, Aguiar et al. (2013) found that about $30 \%$ of foregone market hours are allocated to home production at business cycle frequencies. I choose to set $b=0.4$ in the baseline calibration. However I also report results for different values of this parameter in section 5 .

The parameters of the technological process, $\delta_{Z}$ and $\sigma_{\varepsilon} z$, are chosen in order to match U.S. labor productivity standard deviation and persistence. Finally estimates from Galí and Rabanal (2004) are used to fix the parameters of the monetary policy rule, $\phi_{r}=0.69, \phi_{\pi}=1.35$ and $\phi_{\Delta y}=0.26$.

The model is solved by taking a second-order approximation of the equilibrium conditions around the deterministic steady state. The solution method is explained in Schmitt-Grohé and Uribe (2004). Using a second-order approximation to the equilibrium conditions rather than a first-order approximation has several advantages. As the main purpose of this paper is to study the im- 


\begin{tabular}{|c|c|c|c|c|c|}
\hline & $u$ & $v$ & $\theta$ & $y$ & $z$ \\
\hline \hline Standard deviation & 0.192 & 0.188 & 0.37 & 0.033 & 0.02 \\
\hline Autocorrelation & 0.946 & 0.947 & 0.952 & 0.934 & 0.899 \\
\hline Correlation & 1 & -0.86 & -0.96 & -0.858 & -0.412 \\
\hline & $/$ & 1 & 0.962 & 0.818 & 0.439 \\
\hline & $/$ & $/$ & 1 & 0.871 & 0.458 \\
\hline & $/$ & $/$ & $/$ & 1 & 0.711 \\
\hline & $/$ & $/$ & $/$ & & 1 \\
\hline
\end{tabular}

Table 2: Summary Statistics, Quarterly U.S. data, 1951q1 to 2012q4

plications for monetary policy of non-linearities induced by matching frictions, it is crucial to be able to capture these non-linearities. First-order approximations cannot by construction account for non-linearities. Moreover, the use of first-order approximations to the equilibrium conditions may lead to incorrect welfare rankings. In an economy with a distorted steady-state (as is the case here), when welfare is evaluated using a first-order approximation to the equilibrium law of motion of endogenous variables, some second-order terms of the welfare function are omitted while others are included. The resulting welfare criterion will be inaccurate to order two or higher.

\subsection{Labor market volatility and unemployment losses in the baseline economy}

The choice of parameters was guided by the need to take into account the results of studies that have endeavoured to provide estimates of the main parameters of the search and matching model. I now check that the model is also consistent with the behavior of the U.S. economy at the aggregate level by comparing the simulated moments of some key variables to their empirical counterparts in U.S. data over the period 1951q1 to 2012q4. In order to compute those empirical moments, I use the data for unemployment and vacancies described previously as well as series for output and labor productivity taken from the Bureau of Labor Statistics MSPC program ${ }^{2}$. I take quarterly averages of monthly series. Fluctuations at business cycle frequencies are isolated by taking the difference between the log of the variables and a Hodrick-Prescott filter with smoothing parameter $10^{5}$, as is common practice in the literature. Table 2 presents these empirical moments.

In order to compute simulated moments from the model, I generate quarterly series for all variables by perturbating the model with i.i.d technology shocks $\varepsilon_{t}^{Z} \backsim\left(0, \sigma_{\varepsilon^{Z}}^{2}\right)$. I discard the first 100 quarters of simulation and obtain 248

\footnotetext{
${ }^{2}$ Output is quarterly real output in the non farm business sector (series ID PRS85006043) and labor productivity is quarterly real output per job in the non farm business sector (series ID PRS85006163)
} 


\begin{tabular}{|c|c|c|c|c|c|}
\hline & $u$ & $v$ & $\theta$ & $y$ & $z$ \\
\hline \hline Standard deviation & 0.135 & 0.156 & 0.202 & 0.016 & 0.016 \\
\hline Autocorrelation & 0.414 & -0.19 & -0.055 & 0.932 & 0.82 \\
\hline Correlation & 1 & -0.808 & -0.89 & -0.296 & 0.254 \\
\hline & $/$ & 1 & 0.988 & 0.364 & -0.08 \\
\hline & $/$ & $/$ & 1 & 0.362 & -0.13 \\
\hline & $/$ & $/$ & $/$ & 1 & 0.845 \\
\hline & $/$ & $/$ & $/$ & & 1 \\
\hline Simulated means & 0.0622 & 0.0795 & 0.586 & 0.9375 & 1 \\
\hline
\end{tabular}

Table 3: Model - Simulated moments in the baseline economy

quarters of simulated data corresponding to data from 1951q1 to $2012 \mathrm{q} 4$ and detrend it with an HP filter of smoothing parameter $10^{5}$. I repeat this exercise a hundred times and compute the standard deviations and autocorrelations of variables and correlations between variables in each corresponding sample. Table 3 presents the mean standard deviations, autocorrelations and correlations across samples and the means of the variables generated by the model. The model does a fairly good job at amplifying technology shocks and generating a significant amount of labor market volatility. It also reproduces the strong negative correlation between unemployment and vacancies - the Beveridge Curve. However, it does not perform well along an important dimension; the autocorrelations of labor market variables are substantially lower than in the data. Moreover the correlations of vacancies and labor market tighness with labor productivity are not significantly different from zero and unemployment and labor productivity are positively correlated. Although these correlations are at odds with those presented in Table 2, they are consistent with what we observe in the data over the post-1985 period (Barnichon 2007 and table 4 in Pizzo 2014).

The last line in Table 3 presents the simulated means of the variables in the model. Unemployment losses due to business cycles are modest in the baseline economy - average unemployment is only 0.22 percentage points higher than steady-state unemployment. As expected from the analysis carried out in section 3, this is due to two elements. First, the model generates a negative covariance between the unemployment rate and the job finding rate equal to -4.4 , measuring both rates in percentage points. Second, the mean job-finding rate in the fluctuating economy $E\left(p_{t}\right)=0.5468$ is lower than the steady-state job-finding rate $p=0.5562$. The latter result can be understood by deriving an analytical expression for the job-finding rate. Define $x_{t}=\frac{Z_{t}}{\mu_{t}}$ as real revenues and assume all variables in the job creation equation (7) are covariance stationary. Under the maintained assumption that $\alpha=0.5$, we can write

$$
E\left(p_{t}\right)=\frac{\mu^{2}}{\kappa\left(1-(1-\rho) E\left(\beta_{t}\right)\right)}\left[E\left(x_{t}\right)-E\left(w_{t}\right)+(1-\rho) \frac{\kappa}{\mu^{2}} \operatorname{cov}\left(\beta_{t}, p_{t}\right)\right]
$$




\begin{tabular}{|c|c|c|c|c|c|}
\hline & $u$ & $v$ & $\theta$ & $y$ & $z$ \\
\hline \hline Standard deviation & 0.283 & 0.201 & 0.308 & 0.034 & 0.016 \\
\hline Autocorrelation & 0.91 & 0.761 & 0.832 & 0.883 & 0.82 \\
\hline Correlation & 1 & -0.897 & -0.948 & -0.974 & -0.958 \\
\hline & $/$ & 1 & 0.989 & 0.961 & 0.983 \\
\hline & $/$ & $/$ & 1 & 0.991 & 0.993 \\
\hline & $/$ & $/$ & $/$ & 1 & 0.983 \\
\hline & $/$ & $/$ & $/$ & & 1 \\
\hline Simulated means & 0.0644 & 0.0806 & 0.6127 & 0.9357 & 1 \\
\hline
\end{tabular}

Table 4: Model - Simulated moments with technology shocks and a strong response to inflation

A positive technology shock results in a fall in marginal cost. This negative comovement between labor productivity and marginal cost tends to reduce average real revenues $\left(E\left(x_{t}\right)<x\right)$. This effect has a negative impact on job creation. However, two other effects tend to favor job creation. First, since wages are a concave function of technology, we have that $E\left(w_{t}\right)<w$. Second, the stochastic discount factor, which is inversely related to consumption growth, co-moves with the job finding rate. That is, firms put a larger weight on the future in expansions when the future gains of creating a vacancy today are high than they do in recessions, when those gains are low. Quantitatively, the negative impact of lower average real revenues on job creation dominates and we have that $E\left(p_{t}\right)<p$. The job-finding rate is lower in an economy with business cycles than in steady-state.

Through their influence on markups, alternative monetary policies will lead to different outcomes in terms of average unemployment. I now examine the behavior of the economy under price stability. I focus on this specific policy as it has been shown to be the optimal policy in a wide range of studies (Walsh 2014), including some using a framework similar to the one presented in this paper (Faia 2009, Ravenna and Walsh 2012).

\subsection{A trade-off between inflation volatility and average unemployment}

Table 4 presents some simulated moments of the model under a policy of price stability (that is, $\phi_{r}=\phi_{\Delta y}=0$ and an arbitrarily large weight is put on inflation). The labor market becomes more volatile under this policy as the standard deviation of unemployment more than doubles. Mean unemployment is higher by about 0.44 percentage points than in steady-state. This increase in unemployment is not due to a greater asymmetry in job-finding rate fluctuations since the mean job-finding rate $E\left(p_{t}\right)=0.5519$ is higher under price stability than in the baseline economy. Because markups are constant under price stability, av- 
erage real revenues are not affected by business cycles. This explains the slight difference in the average job-finding rate between the two regimes. Rather, the unemployment losses are due to the spectacular increase in the covariance between the job-finding rate and the unemployment rate at -22.5 . That is, it is the increase in the volatility of the job-finding rate that accounts for the rise in average unemployment. This result can be understood by solving forward the job creation equation.

$$
\frac{\kappa}{q\left(\theta_{t}\right)}=\sum_{j=0}^{\infty} E_{t} \beta^{j}\left(\frac{C_{t+j}}{C_{t}}\right)^{-\sigma}(1-\rho)^{j}\left(\frac{Z_{t+j}}{\mu_{t+j}}-\omega Z_{t+j}^{\gamma}\right)
$$
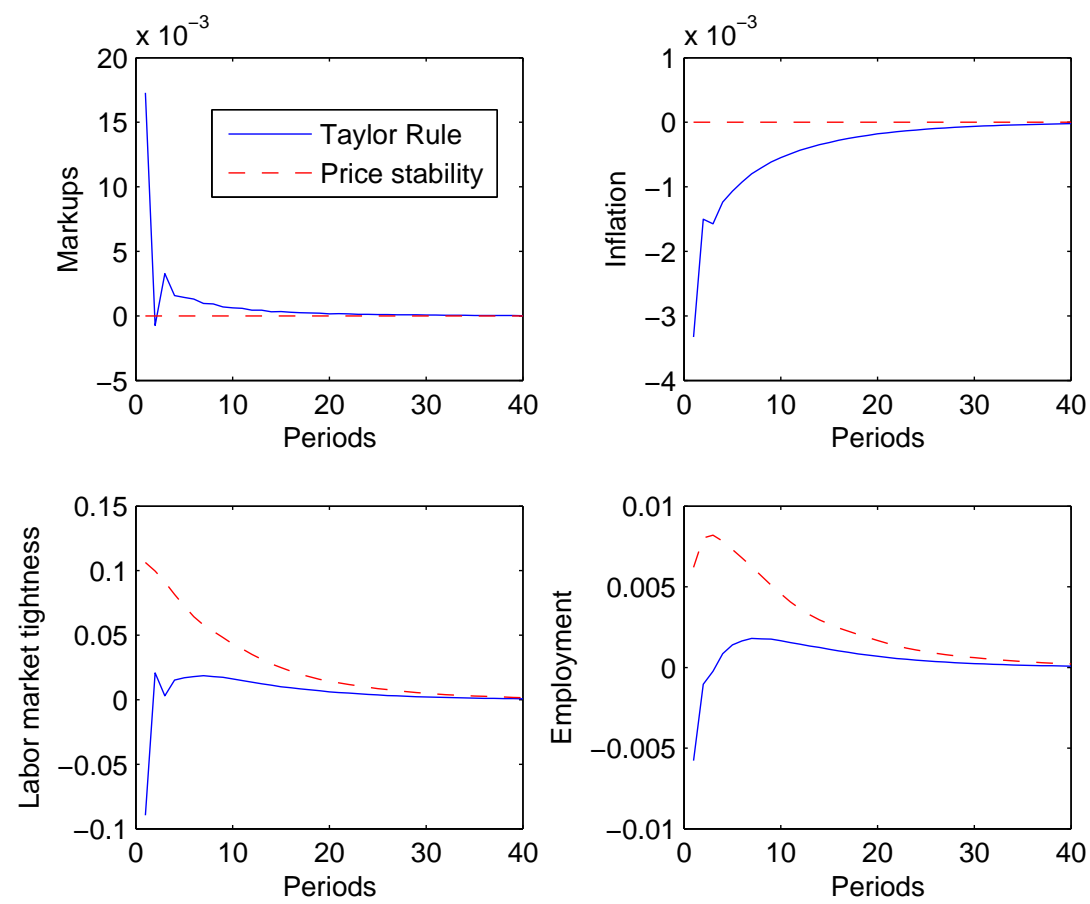

Figure 2: Impulse responses of selected variables following a positive productivity shock of one standard deviation under different rules: (1) Taylor rule, (2) Price Stability

This equation states that vacancy posting today is driven by the sum of future expected discounted real revenues minus wage payments. Since the paths of labor productivity and real wages are identical under the policies considered, the differences in vacancy posting activity must come from differences in the path of markups. Markups are influenced by monetary policy as they depend on current inflation and future expected inflation through equation (8). Thus, through its 


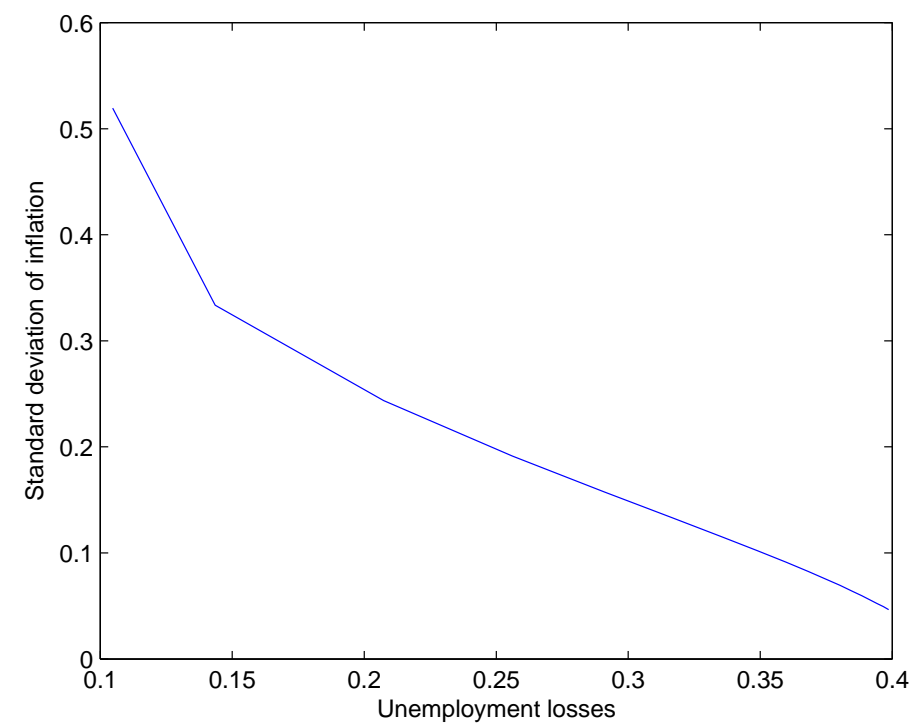

Figure 3: Standard deviation of inflation and unemployment losses (both in percentage points) under alternative monetary regimes

impact on markups, monetary policy has an influence on the reaction of labor market activity to technology shocks. A positive technology shock leads to a decrease in marginal cost. Under price stability, the monetary authority reacts aggressively by cutting interest rates. This leads to an expansion in aggregate demand and forces firms to hires more workers in order to meet demand. This increase in hiring activities raises marginal cost back to its previous level. Firms do not have to adjust prices and markups remain constant. Under the Taylor rule considered in the baseline economy, the monetary authority does not cut interest rates as aggressively as under price stability. As a result, the expansion in aggregate demand is limited. Since firms can now produce the same level of output with less workers, they actually cut employment on impact. Markups go upwards at the time of the shock because marginal cost decreases and firms are unable to decrease prices as much as they would like to. In the periods following the shock, firms start adjusting prices and employment increases, but much less than under price stability. Figure 1 illustrates this graphically by plotting the response of markups, inflation, labor market tightness and employment both under price stability and under the baseline Taylor rule following a positive productivity shock of one standard deviation.

Thus, by engineering procyclical markups, the monetary authority can limit the impact of technology shocks on hiring. This will tend to reduce the magnitude of fluctuations in the job-finding rate and lead to higher average unemployment. 
However, in order to generate procyclical markups, the central bank must tolerate deviations from price stability. The preceding analysis suggests that the monetary authority faces a trade-off between inflation volatility and average unemployment. This intuition can be confirmed with a simple exercise. I assume that the monetary authority responds only to inflation and compute $E\left(u_{t}\right)-u$ for different values of $\phi_{\pi}$ ranging from 1.5 to 10 . Figure 3 plots the standard deviation of inflation and the unemployment losses under those different monetary rules. It shows that there is a clear relationship between inflation volatility and average unemployment. A higher standard deviation of inflation is associated with a lower level of unemployment.

The next section undertakes a normative analysis. It studies the characteristics of the optimal policy and provides a welfare ranking of alternative policies. Notably, it tries to answer the following question: is a policy of price stability still nearly optimal in this framework, despite its costs in terms of higher average unemployment?

\section{Optimal policy and welfare analysis}

In a standard New-Keynesian model, the monetary authority does not face a trade-off between stabilizing inflation and real activity. This conclusion is no longer valid in the presence of search and matching frictions in the labor market. Whenever job creation is inefficient, the monetary authority has an incentive to deviate from price stability to stabilize labor market activity (Faia 2009). However, quantitatively, the level of welfare attained by a policy of price stability is very close to the one obtained under the optimal policy. This point is forcefully emphasized in Ravenna and Walsh (2012). This section examines whether this conclusion is still valid within the framework presented in this paper.

\subsection{Ramsey-optimal monetary policy}

The optimal policy is the process $\left\{I_{t}\right\}$ associated with the competitive equilibrium that yields the highest level of welfare. The monetary authority chooses the optimal paths of $\left\{C_{t}, I_{t}, N_{t}, \mu_{t}, \theta_{t}, \pi_{t}, v_{t}\right\}$ that maximize the present discounted value of household utility, taking as constraints equations (1), (4), (7),(8), (11) and the definition of labor market tightness. This problem can be simplified in several ways. First, note that once the paths of consumption and inflation are known, the path of the interest rate can be backed out from the Euler equation. Similarly, once the paths of labor market tightness and employment are known, the path of vacancies can be obtained. Thus, the problem can be transformed in one in which the Ramsey planner chooses $\left\{C_{t}, N_{t}, \mu_{t}, \theta_{t}, \pi_{t}\right\}$ subject to the law of motion of employment (1), the job creation equation (7), the non-linear Phillips curve (8) and the resource constraint (11). 


$$
\begin{gathered}
\operatorname{Max}_{C_{t}, N_{t}, \mu_{t}, \theta_{t}, \pi_{t}} E_{0} \sum_{t=0}^{\infty} \beta^{t}\left(\frac{C_{t}^{1-\sigma}}{1-\sigma}\right. \\
+\lambda_{1 t}\left[Z_{t} N_{t}\left(1-\frac{\phi^{p}}{2}\left(\Pi_{t}-1\right)^{2}\right)-\kappa \theta_{t}\left(1-(1-\rho) N_{t-1}\right)+b\left(1-N_{t}\right)-C_{t}\right] \\
+\lambda_{2 t}\left[(1-\rho) N_{t-1}+\mu\left(1-(1-\rho) N_{t-1}\right) \theta_{t}^{1-\alpha}-N_{t}\right] \\
+\lambda_{3 t}\left[C_{t}^{-\sigma}\left[Z_{t} m c_{t}-\omega Z_{t}^{\gamma}-\frac{\kappa}{\mu} \theta_{t}^{\alpha}\right]+E_{t} \beta C_{t+1}^{-\sigma}(1-\rho) \frac{\kappa}{\mu} \theta_{t+1}^{\alpha}\right] \\
\left.+\lambda_{4 t}\left[C_{t}^{-\sigma}\left(1-\epsilon+\varepsilon m c_{t}-\phi^{p} \Pi_{t}\left(\Pi_{t}-1\right)\right)+E_{t} \beta C_{t+1}^{-\sigma} \phi^{p} \Pi_{t+1}\left(\Pi_{t+1}-1\right) \frac{Z_{t+1} N_{t+1}}{Z_{t} N_{t}}=0\right]\right)
\end{gathered}
$$

where $\left\{\lambda_{1 t}, \lambda_{2 t}, \lambda_{3 t}, \lambda_{4 t}\right\}$ represent sequences of Lagrange multipliers associated with the four constraints. Due to the forward-looking nature of the last two constraints, this problem is non-stationary. This issue can be addressed by introducing lagged multipliers $\lambda_{3,-1}, \lambda_{4,-1}$ corresponding to the forward-looking constraints in the initial period. Their value is set equal to their solution in steady-state. Thus I study the behavior of the economy after the effects of an initial start-up period have worn away, that is I assume that the central bank has long been following the optimal policy (King and Wolman 1999). A system of nine equations (the four equations just mentioned and five firstorder conditions) and nine unknowns (the five endogenous variables and the four Lagrange multipliers) is obtained. It is solved numerically with second-order perturbation methods. The optimal long run inflation rate in this economy is equal to zero (see the appendix). In what follows, I study the behavior of the economy under the optimal policy in response to technology shocks. I compare the outcomes in terms of labor market volatility and average unemployment to those that are obtained in the baseline economy and under a policy of price stability. Table 5 reports the simulated moments of selected variables of the model under the optimal policy. 


\begin{tabular}{|c|c|c|c|c|c|}
\hline & $u$ & $v$ & $\theta$ & $y$ & $z$ \\
\hline \hline Standard deviation & 0.062 & 0.041 & 0.065 & 0.019 & 0.016 \\
\hline Autocorrelation & 0.922 & 0.753 & 0.832 & 0.844 & 0.82 \\
\hline Correlation & 1 & -0.912 & -0.968 & -0.955 & -0.931 \\
\hline & $/$ & 1 & 0.988 & 0.983 & 0.985 \\
\hline & $/$ & $/$ & 1 & 0.992 & 0.986 \\
\hline & $/$ & $/$ & $/$ & 1 & 0.997 \\
\hline & $/$ & $/$ & $/$ & & 1 \\
\hline Simulated means & 0.0613 & 0.0804 & 0.592 & 0.9384 & 1 \\
\hline
\end{tabular}

Table 5: Model - Simulated moments with technology shocks under the optimal monetary policy
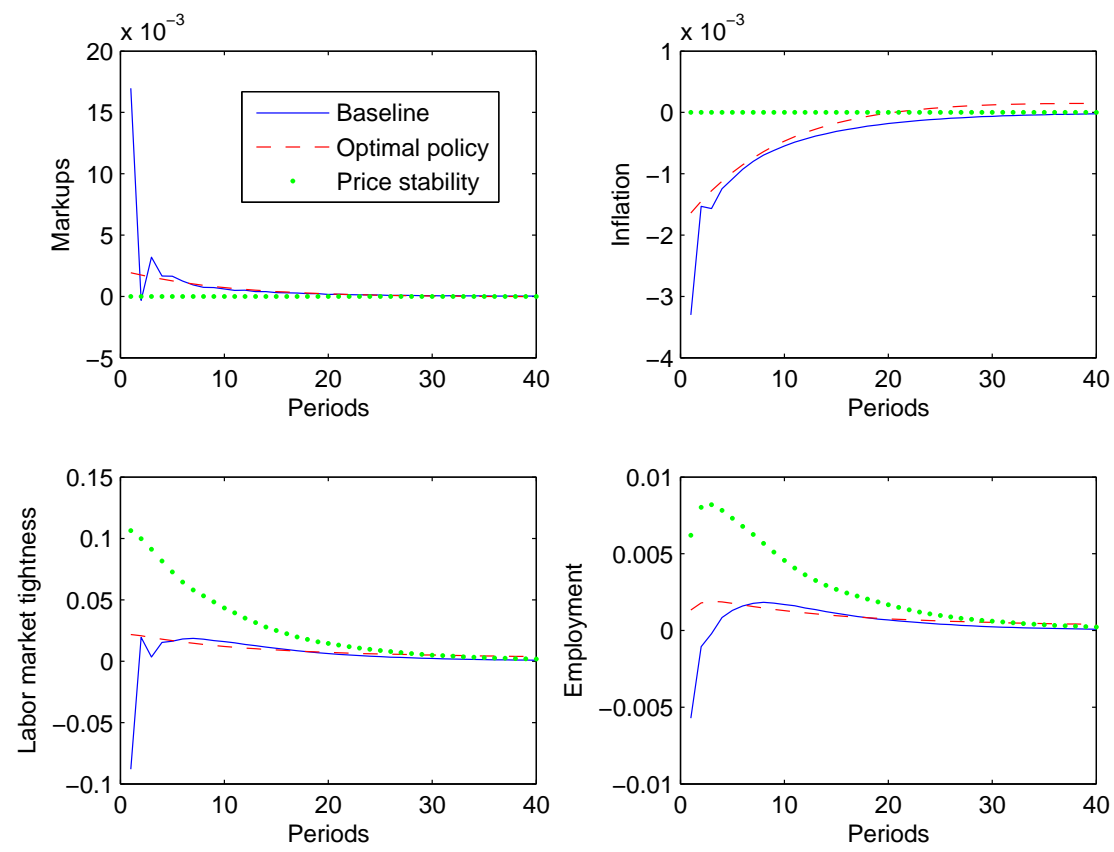

Figure 4: Impulse responses of selected variables to a positive productivity shock of one standard deviation under different rules: (1) Baseline, (2) Ramsey policy, (3) Price Stability

Labor market volatility is much lower than under the previous policies. This lower volatility is reflected in the value of the covariance between the unemployment rate and the job finding rate which stands at -1.4 . Because the average job-finding rate $E\left(p_{t}\right)=0.5517$ is sensibly equal to its value under price stability, the unemployment losses due to business cycles are much lower - average 
unemployment is equal to $6.13 \%$. Figure 4 compares the reaction of markups, inflation, labor market tightness and employment to a positive productivity shock under three different monetary policies - the baseline Taylor rule, the optimal policy and the policy of price stability. The behavior of markups is smoother under the optimal policy than under a Taylor rule and this enables the Ramsey planner to avoid the large drops in labor market tightness and employment in the first period after the shock. However, the procyclicality of markups still helps cushion the effects of the shock on hiring. As a result, the reactions of labor market tightness and employment are lower than under price stability. This smooth, yet procyclical, behavior of markups helps explain why labor market volatility is much lower than under the two policies considered in section 4 .

\subsection{Welfare analysis}

The preceding analysis shows that the qualitative behavior of the economy is markedly different under the optimal policy than under price stability. However, as emphasized in the introduction, previous studies have found that adopting the optimal policy rather than a policy of price stability brings only modest welfare gains. In this section, I evaluate whether this conclusion is still valid within the framework presented in this paper. In order to do so, I compare the levels of lifetime utility associated with the two policies. Welfare will be characterized conditional upon the initial steady-state being the deterministic steady-state. Since the deterministic steady-state is the same in the two regimes, this ensures that the economy begins from the same initial point under both policies and that the welfare measure takes into account the transition path to the stochastic steady-state associated with each policy. Following the method and notations used in Schmitt-Grohe and Uribe (2005), the equilibrium process for consumption associated with a particular policy regime will be denoted by $\left\{c_{t}\right\}$. Welfare, $V_{0}$, is measured as the conditional expectation of lifetime utility as of time 0 evaluated at $\left\{c_{t}\right\}$. Formally

$$
V_{0}=E_{0} \sum_{t=0}^{\infty} \beta^{t} U\left(c_{t}\right)
$$

The levels of welfare associated with the Ramsey regime $V_{0}^{r}$ and the regime of price stability $V_{0}^{P S}$ are

$$
\begin{gathered}
V_{0}^{r}=E_{0} \sum_{t=0}^{\infty} \beta^{t} U\left(c_{t}^{r}\right) \\
V_{0}^{P S}=E_{0} \sum_{t=0}^{\infty} \beta^{t} U\left(c_{t}^{P S}\right)
\end{gathered}
$$


where $\left\{c_{t}^{r}\right\}$ and $\left\{c_{t}^{P S}\right\}$ are the consumption processes under the Ramsey regime and the regime of price stability, respectively. The welfare cost of adopting a regime of price stability instead of the Ramsey regime, $\lambda$, is measured as the fraction of the Ramsey consumption process that a household would be willing to give up to be as well-off under the price stability regime as under the Ramsey regime. $\lambda$ is implicitly defined as

$$
V_{0}^{P S}=E_{0} \sum_{t=0}^{\infty} \beta^{t} U\left(c_{t}^{r}(1-\lambda)\right)
$$

Given the form of the utility function $U(c)=\frac{c^{1-\sigma}}{1-\sigma}$, this yields

$$
\lambda=1-\left(\frac{V_{0}^{P S}}{V_{0}^{r}}\right)^{\frac{1}{1-\sigma}}
$$

\begin{tabular}{|c|c|c|c|c|c|c|}
\hline & $C^{P S}$ & $\sigma\left(C^{P S}\right)$ & $C^{R}$ & $\sigma\left(C^{R}\right)$ & $\lambda$ & $\begin{array}{c}\text { \% of gain due to } \\
\text { increase in } \bar{C}\end{array}$ \\
\hline \hline$b=0$ & 0.9266 & 0.033 & 0.9295 & 0.017 & $0.43 \%$ & $72.1 \%$ \\
\hline$b=0.4$ & 0.9529 & 0.024 & 0.9542 & 0.017 & $0.18 \%$ & $77.8 \%$ \\
\hline$b=0.6$ & 0.9659 & 0.020 & 0.9665 & 0.017 & $0.09 \%$ & $69 \%$ \\
\hline$b=0.7$ & 0.9723 & 0.018 & 0.9727 & 0.016 & $0.05 \%$ & $82.3 \%$ \\
\hline
\end{tabular}

Table 6: Welfare analysis - Optimal policy versus Price stability

The welfare gain is computed for different values of $b$, the flow value of unemployment. Table 6 reports this welfare measure along with the mean and standard deviation of consumption under each policy. The gain in aggregate welfare is $0.18 \%$ in the baseline calibration. This gain is an order of magnitude higher than what has been found in other studies using a similar framework (Thomas 2008, Faia 2009). Section 5.3 provides an explanation for this discrepancy in the findings. Adopting the Ramsey policy yields a modest decline in consumption volatility and a $0.14 \%$ increase in average consumption. The final column gives an estimate of the welfare gain that is due to the increase in average consumption. Note that households would be willing to pay exactly $0.14 \%$ ((0.9542 - 0.9529)/0.9542) of the Ramsey consumption process for mean consumption to attain its level under the optimal policy. Thus we can deduce that approximately $77.8 \%(0.14 / 0.18 \times 100)$ of the total gain in welfare is due to the increase in average consumption. It is possible to understand where this increase comes from by considering equation (11), the resource constraint of the economy. Since the mean level of vacancies is sensibly the same under the two policies, it is clear that the Ramsey planner attains a higher level of consumption by exploiting the long-run trade-off between inflation volatility and average unemployment. By allowing for deviations from price stability $(\Pi=1)$, the optimal policy is able to obtain an increase in mean employment. 
Table 6 also shows that the welfare cost of price stability is a decreasing function of the flow value of unemployment. For $b=0$, the welfare gain attains $0.43 \%$ of the Ramsey consumption process. Since the wage process is exogenous, a change in the flow value of unemployment barely affects the cyclical properties of the model under price stability. Average unemployment is about the same for values of $b$ ranging from 0 to 0.7 . However, this parameter is critical for welfare as it determines how given unemployment losses translate in consumption losses. When $b$ is high, unemployment losses are not very costly from the point of view of the household since unemployed household members generate about as much revenues as if they were employed. For $b=0.7$, a 0.25 percentage points difference in average unemployment between the Ramsey policy and the policy of price stability results in a mere 0.04 difference in average consumption. However for $b=0$, the 0.37 percentage points difference in average unemployment between the two policies leads to a more sizeable 0.31 difference in average consumption. It follows that the value of $b$ shapes monetary policy trade-offs. The Ramsey planner has much more incentive to use costly inflation volatility in order to stabilize unemployment fluctuations when the flow value of unemployment is low. Indeed, the standard deviation of inflation under the Ramsey regime nearly doubles when $b$ goes from 0 to 0.7 .

Thus, by deviating significantly from price stability, the central bank is able to lower average unemployment and bring about an increase in average consumption. This increase accounts for the bulk of the welfare gains achieved by the optimal policy. This analysis points to the importance of the asymmetry in unemployment fluctuations in shaping welfare outcomes. In the absence of such asymmetry, the central bank's actions would be largely ineffective at influencing average unemployment and consumption.

\subsection{The performance of simple rules}

This section complements the preceding analysis by evaluating the performance of alternative simple and implementable rules. The implementability condition requires the rules to deliver uniqueness of the rational expectations equilibrium. Simplicity implies that only rules for which the interest rate is set as a function of easily observable macroeconomic indicators are considered. Specifically, I consider rules that respond to the output gap, the employment gap or output growth alongside inflation. I search the grid of parameters $\left\{\phi_{\pi}, \phi_{y}, \phi_{N}, \phi_{\Delta y}\right\}$ over the intervals $[1.5,5]$ for $\phi_{\pi}$ and $[0,0.5]$ for $\phi_{N}, \phi_{y}, \phi_{\Delta y}$ for the parameter combination that yields the highest level of welfare.

Several results emerge. First, in the baseline calibration, the rule that performs best features a vigorous response to both inflation and the employment gap, $\phi_{y}=2.5$ and $\phi_{N}=0.5$, and yields a level of welfare close to the one attained under the optimal policy (the welfare cost of adopting this policy rather than the Ramsey policy is equal to $\lambda=0.0087$ ). Second, responding solely and strongly 
to inflation is always welfare detrimental. This can be seen in figures 5,6 and 7 in the appendix which plot the level of conditional welfare according to the response to inflation and the employment gap for different values of $b$. Finally, the relative weight that a policymaker should place on inflation is an increasing function of the flow value of unemployment. When $b=0$, a mild respond to inflation alongside a strong response to employment is warranted. However, when $b=0.7$, this policy does not perform as well. In that case, the monetary policymaker should stabilize inflation more vigorously.

\subsection{Relation to the literature}

This paper builds on a very rich literature that has endeavoured to introduce the modern theory of unemployment in dynamic stochastic general equilibrium models and study how monetary policy should trade-off between inflation and unemployment stabilization. A robust result of this literature is that even when job creation is inefficient, the monetary authority should focus almost exclusively on stabilizing prices. This paper comes up with a different conclusion, namely that the asymmetric nature of unemployment fluctuations tends to generate important business cycle costs and a meaningful tradeoff between inflation and unemployment stabilization for the monetary policymaker. The aim of this section is to explain the discrepancy between these findings.

First, an important number of papers rely on first-order approximations to the equilibrium conditions when solving the model. This is the case of papers by Thomas (2008), Blanchard and Gali (2010) and Ravenna and Walsh (2011) who all follow the linear quadratic approach to studying optimal monetary policy. As emphasized in section 4.1, by using first-order approximations, one suppresses by construction any non-linearity from the analysis. In that case, the unconditional mean of a variable in the stochastic steady-state is not different from its deterministic steady-state value, and the way monetary policy is conducted has no influence on mean unemployment. I have argued in the previous section that most of the welfare costs of a policy of price stability are due to mean effects. Thus it is not surprising that those papers find very small costs of price stability when real wages are rigid. However, Thomas (2008) does find signifcant costs of price stability in the presence of staggered nominal wages. This suggests that the figures reported here could be higher if monetary policy was allowed to have a direct leverage over real wages.

Other papers such as Faia $(2008,2009)$ and Ravenna \& Walsh (2012) have relied on second-order approximations to the equilibrium conditions. As emphasized in section 3, the size of the employment losses due to business cycles depends on the volatility of the job-finding rate. Therefore, the model must generate enough amplification in response to technology shocks for the cost of unemployment fluctuations to be substantial. It has been well known since at least Shimer (2005) that models with search and matching frictions and flexible wages 
generate very little volatility in labor market variables. Following a shock, the immediate adjustment of the wage does not leave any incentive for firms to adjust through the employment margin. Thus, in the flexible wage model of Faia (2009), mean unemployment must be very close to its steady-state value. Not surprisingly, in her baseline calibration, the optimal deviations from price stability are negligible. However, it is worth noting that only a small degree of wage rigidity is necessary for the model to amplifiy shocks and for average unemployment to differ significantly from its steady-state value. In this paper, the elasticity of wages with respect to technology is set to 0.8 , consistent with empirical estimates in Haefke et al. (2013). Finally, the results presented here are consistent with some of the findings in Ravenna and Walsh (2012). These authors use a similar framework with wage rigidity and find that the gains from deviating from price stability are larger in economies with more volatile labor flows. Indeed, given the asymmetric nature of unemployment fluctuations in the presence of search and matching frictions, the more volatile is unemployment, the larger is average unemployment and the greater are the mean consumption gains that a central bank can achieve by deviating from price stability.

\section{An extension with imperfect unemployment in- surance}

Several authors (Faia 2008, Walsh 2014) have argued that the presence of imperfect unemployment insurance should make unemployment fluctuations more costly and reinforce policymaker's incentives to stabilize labor market variables. I examine this possiblity by introducing imperfect unemployment insurance in the model of section 2. Following the efficiency wages literature (Alexopolous 2004, Nakajima 2010), I assume that individual household members are not allowed to participate in asset markets; it is the household itself that is in charge of savings decisions. This assumption has the advantage of limiting the amount of heterogeneity between individuals and helps keep the model tractable.

\subsection{Modifications to the existing model}

The household has expected utility

$$
E_{0} \sum_{t=0}^{\infty} \beta^{t}\left[N_{t} \frac{C_{e, t}^{1-\sigma}}{1-\sigma}+\left(1-N_{t}\right) \frac{C_{u, t}^{1-\sigma}}{1-\sigma}\right]
$$

where $C_{e, t}$ and $C_{u, t}$ are the date $t$ consumption levels of employed and unemployed individuals, respectively. The household receives profits from firms $\Pi_{t}^{r}$, can acquire risk-free bonds that promise a unit of currency tomorrow and cost $\left(1+I_{t}\right)^{-1}$ today, and redistributes an amount $\Omega_{t}$ equally among household members. Its flow budget constraint is given by

$$
P_{t} \Omega_{t}+\left(1+I_{t}\right)^{-1} B_{t+1}=B_{t}+P_{t} \Pi_{t}^{r}
$$


Employed individuals are paid a wage $w_{t}$ by firms, receive the amount $\Omega_{t}$ and have to pay a fee $f_{t}$ to fund the unemployment insurance system. Unemployment individuals receive $\Omega_{t}$, the flow value of unemployment $b$ and unemployment benefits $w_{t}^{u}$. The budget constraints of employed and unemployed individuals are accordingly given by

$$
\begin{aligned}
& C_{e, t}=w_{t}+\Omega_{t}+f_{t} \\
& C_{u, t}=b+\Omega_{t}+w_{t}^{u}
\end{aligned}
$$

The unemployment insurance system runs a balanced budget

$$
N_{t} f_{t}=\left(1-N_{t}\right) w_{t}^{u}
$$

Households choose $\Omega_{t}$ and $B_{t+1}$ to maximize the average utility of its members, equation (14), subject to the three budget constraints (15), (16), (17). The Euler equation describing the household's optimal consumption path now involves the average marginal utilities at date $t$ and $t+1$

$$
\beta E_{t} \frac{1+I_{t}}{\Pi_{t+1}}\left(\frac{N_{t+1} C_{e, t+1}^{-\sigma}+\left(1-N_{t+1}\right) C_{u, t+1}^{-\sigma}}{N_{t} C_{e, t}^{-\sigma}+\left(1-N_{t}\right) C_{u, t}^{-\sigma}}\right)=1
$$

On the firm side, job creation and pricing decisions are affected by the introduction of imperfect unemployment insurance to the extent that the household's stochastic discount factor is modified. Moreover, it can be verified that aggregate consumption $C_{t}=N_{t} C_{e, t}+\left(1-N_{t}\right) C_{u, t}$ is still given by equation (11). We can now define an equilibrium.

Definition: A competitive equilibrium is a set of plans $\left\{C_{e, t}, C_{u, t}, I_{t}, N_{t}, \mu_{t}, \theta_{t}, \pi_{t}, w_{t}, f_{t}\right\}$ satisfying equations (1), (7), (8), (9), (10), (16), (17), (18) and (19) given a specification for the exogenous process $\left\{Z_{t}\right\}$ and initial conditions $N_{-1}$ and $\theta_{-1}$.

\subsection{Qualitative analysis}

In order to build intuition for the results that will be obtained in the quantitative analysis, I first seek to obtain analytical results. Let $R_{t}=\frac{C_{u, t}}{C_{e, t}}$ denote the ratio of the level of consumption of the unemployed to that of the employed. Given that $C_{t}=N_{t} C_{e, t}+\left(1-N_{t}\right) C_{u, t}$, it follows that

$$
\begin{aligned}
C_{e, t} & =\frac{1}{N_{t}+\left(1-N_{t}\right) R_{t}} C_{t} \\
C_{u, t} & =\frac{R_{t}}{N_{t}+\left(1-N_{t}\right) R_{t}} C_{t}
\end{aligned}
$$

A couple of simplifying assumptions will make the analysis easier. 
Assumption 1: $R_{t}=R \forall t$.

Assumption 2: Utility is given by the $\log$ of consumption, $U\left(C_{t}\right)=\log \left(C_{t}\right)$.

Period utility $U_{t}$ can now be written

$$
U_{t}=\ln \left(C_{t}\right)+\left(1-N_{t}\right) \ln (R)-\ln \left[N_{t}+\left(1-N_{t}\right) R\right]
$$

Under perfect insurance, when $R=1$, period utility collapses to $U_{t}=\ln \left(C_{t}\right)$. For reasonable values of $N$ and $R$, the extra term due to the presence of imperfect insurance is negative. Because the utility function is concave, the unequal allocation of a given level of aggregate consumption $C_{t}$ between employed and unemployed individuals lowers the level of utility. I now use equation (20) to derive an expression for the welfare cost of business-cycle fluctuations under imperfect insurance. A second-order approximation of $U_{t}$ around its steady-state value gives

$$
E\left(U_{t}\right)-U=\frac{E\left(C_{t}\right)-C}{C}-\frac{1}{2} \frac{\operatorname{Var}\left(C_{t}\right)}{C^{2}}-\tau_{1}\left[E\left(N_{t}\right)-N\right]+\frac{1}{2} \tau_{2} \operatorname{Var}\left(N_{t}\right)
$$

where $\tau_{1}=\ln (R)+\frac{1-R}{N+(1-N) R}$ and $\tau_{2}=\left(\frac{1-R}{N+(1-N) R}\right)^{2} \cdot \tau_{2}$ is unambiguously positive and $\tau_{1}$ is negative for $N>g(R)=\frac{1-R+R \ln (R)}{\ln (R)(R-1)}$. This condition is always verified for $N>0.5$.

Thus, under imperfect insurance, fluctuations in employment have an indirect impact on utility through their influence on consumption but also a direct one as is apparent from the presence of the last two terms. The indirect effect is also at work under perfect insurance but not the direct one $\left(\tau_{1}\right.$ and $\tau_{2}$ are equal to zero when $R=1$ ). Since $\tau_{1}<0$ and $\tau_{2}>0$, both the average level and the volatility of employment have a positive impact on average utility. The intuition for this result is as follows. The utility of the household is a weighted average of the individual utilities of employed and unemployed workers, with the weights given by the employment level. Since $U\left(C_{u, t}\right)<U\left(C_{e, t}\right)$, a lower average employment level decreases mechanically the average utility of the household. Moreover, $C_{e, t}$ and $C_{u, t}$ are both convex functions of $N_{t}$. Thus for a given $C_{t}$, fluctuations in employment tend to increase the average levels of consumption of employed and unemployed workers. In the preceding sections, I found that average employment is lower than steady-state employment and that the variability of employment is positive under all the policies considered. Therefore, a priori, the impact of the introduction of imperfect insurance on the welfare cost of business fluctuations ${ }^{3}$ is ambiguous.

3

It is important to keep in mind that the welfare measure given by equation (21) cannot be used to accurately rank alternative policies. It gives the stochastic 


\subsection{Quantitative analysis}

I now turn to a more quantitative analysis. The calibration of the model is the same as in section 3 . There are two new parameters that need to be calibrated, $R$ and $w^{u}$. Karabarbounis and Chodorow-Reis (2014) find a $21 \%$ decline in expenditure on nondurable goods and services during unemployment and show that the size of this decline is acyclical. In line with those results, unemployment benefits $w_{t}^{u}$ are assumed to evolve so as to target a constant value of $R$ of 0.8 . The two models with perfect and imperfect unemployment insurance share the same steady-state and exhibit almost exactly the same cyclical properties. Thus, the expected utility gap that follows from the introduction of imperfect insurance is approximately equal to

$$
E\left(U_{t}^{P I}\right)-E\left(U_{t}^{I P}\right) \approx \tau_{1}\left[E\left(N_{t}\right)-N\right]-\frac{1}{2} \tau_{2} \operatorname{Var}\left(N_{t}\right)
$$

where $P I$ stands for perfect insurance and $I P$ for imperfect insurance. In the baseline calibration, $\tau_{1}=-0.0207$ and $\tau_{2}=0.0410$. However because the variance of $N_{t}$ is small relative to the employment gap $E\left(N_{t}\right)-N$, the effect arising from the lower average level of employment dominates and expected utility is lower under imperfect insurance. Thus employment fluctuations are more costly under imperfect insurance than under perfect insurance and this should give the central bank additional incentives to stabilize unemployment. I verify whether this conjecture is true by conducting a welfare analysis. Welfare, $V_{0}$, is measured as the conditional expectation of lifetime utility as of time 0 evaluated at $\left\{C_{e t}, C_{u t}, N_{t}\right\}$

$$
V_{0}=E_{0} \sum_{t=0}^{\infty} \beta^{t}\left[N_{t} \frac{C_{e, t}^{1-\sigma}}{1-\sigma}+\left(1-N_{t}\right) \frac{C_{u, t}^{1-\sigma}}{1-\sigma}\right]
$$

The welfare cost of adopting a regime of price stability instead of the Ramsey regime, $\lambda$, is defined as the fraction of the Ramsey consumption processes of employed and unemployed individuals that a household would be willing to give up to be as well off under the Ramsey policy as under a policy of price stability. It is equal to

$$
\lambda=1-\left(\frac{V_{0}^{P S}}{V_{0}^{r}}\right)^{\frac{1}{1-\sigma}}
$$

steady-state level of welfare that is attained by each policy but does not take into account the transition path from the deterministic steady-state to the stochastic steady-state associated with each policy. The aim of this exercise was simply to build some intuition about how the introduction of imperfect insurance may affect welfare. 


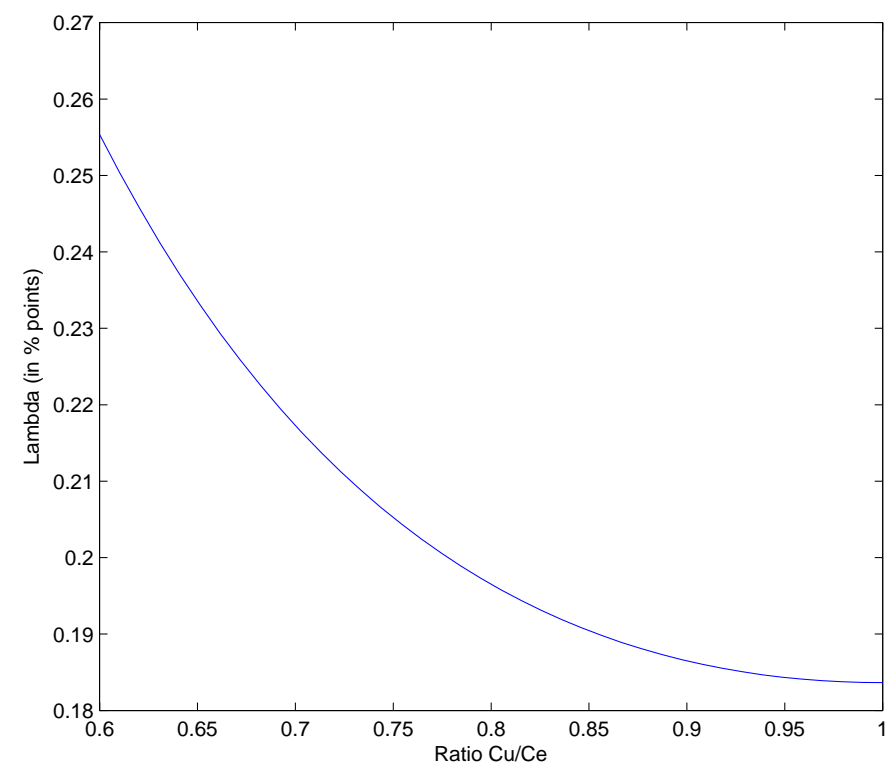

Figure 5: Welfare costs of adopting a policy of price stability according to the ratio of the level of consumption of the unemployed to that of the employed

Since $\tau_{1}$ is an increasing function of $R$, a lower average level of employment is more costly for lower values of the consumption ratio. Thus the welfare gain of adopting the optimal policy rather than a policy of price stability should be a decreasing function of $R$. This intuition is confirmed in figure 5, which plots $\lambda$ and $R$ jointly for values of the consumption ratio ranging from 0.6 to 1 . The additional welfare costs of adopting a policy of price stability brought about by the introduction of imperfect insurance are relatively modest. In the baseline calibration, the welfare costs are only 0.014 percentage points higher than under perfect insurance. This result can be understood by considering equation (21). In the baseline calibration, the coefficient in front of the consumption gap is much larger than that in front of the employment gap. Even when $R=0.6$, $-\tau_{1}=0.1$ is much smaller than $1 / \bar{C}>1$. Thus a decrease in average employment mainly affects welfare through its impact on average consumption. Nakajima (2010) studies the design of optimal monetary policy in a framework with efficiency wages and imperfect unemployment insurance, and finds that the welfare costs of price stability are negligible when the idiosyncratic earning loss due to unemployment is acyclical. This section carries out the same type of exercise in a different model with search and matching frictions in the labor market. In this framework, the existence of a consumption gap between employed and unemployed workers makes the asymmetry in unemployment fluctuations more costly. However, this effect does not seem to be quantitatively important. 
The introduction of imperfect unemployment insurance does not itself call for larger deviations from price stability.

\section{Conclusion}

This theoretical paper studies the design of optimal monetary policy in a New Keynesian model with search and matching frictions in the labor market. It makes two contributions to the existing literature. First, I show that, in that type of framework, the monetary authority faces a trade-off between inflation volatility and average unemployment. In the presence of matching frictions, unemployment rises more and faster in a recession than it decreases in an expansion. A central bank willing to tolerate moderate deviations from price stability is able to generate procyclical markups that dampen the impact of technology shocks on labor market volatility. Because of the asymmetric nature of unemployment fluctuations, such a policy leads to higher average employment.

Second, I find that the optimal policy deviates markedly from price stability and reaps important welfare gains. Most of those gains arise from the increase in average employment achieved by the Ramsey policymaker. This result shows the importance of the asymmetric nature of unemployment fluctuations in shaping monetary policy trade-offs. In the absence of such asymmetry, monetary policy would be unable to influence average unemployment and the welfare gains of adopting the optimal policy would accordingly be smaller. Related papers have found that monetary policy should focus mainly on stabilizing prices. This discrepancy in the results follows from the necessity to use both non-linear solution methods and a model featuring a strong enough amplification mechanism to capture the substantial costs brought about by asymmetric unemployment fluctuations. 


\section{References}

[1] Aguiar, M., Hurst, E., Karabarbounis, L., 2013. "Time Use During the Great Recession," American Economic Review, 103(5), 1664-1696

[2] Alexopoulos, M., 2003. "Unemployment and the Business Cycle," Journal of Monetary Economics, 51, 277-298

[3] Barnichon, R., 2010. "Productivity and Unemployment Over the Business Cycle," Journal of Monetary Economics, 57(8), 1013-1025

[4] Bilbiie, F. O. "Monetary and Fiscal Policy Analysis with Imperfect Competition and Nominal Rigidities," Lecture Notes

[5] Bilbiie, F. O., Fujiwara, I., Ghironi, F., 2014. "Optimal Monetary Policy with Endogenous Entry and Product Variety," Journal of Monetary Economics, 64, 1-20

[6] Benhabib, J., Rogerson, R., Wright, R., 1991. "Homework in Macroeconomics: Household Production and Aggregate Fluctuations," Journal of Political Economy, 99(6), 1166-1187

[7] Blanchard, O. J., Galí, J., 2010. "Labor Market Frictions and Monetary Policy: A New Keynesian Model with Unemployment", American Economic Journal: Macroeconomics, 152 (2), 1-30.

[8] Faia, E., 2008. "Optimal monetary policy rules with labor market frictions," Journal of Economic Dynamics and Control 32(5), 1357-1370.

[9] Faia, E., 2009. "Ramsey monetary policy with labor market frictions," Journal of Monetary Economics, 56, 570-582.

[10] Galí, J., Rabanal, P., 2004. "Technology Shocks and Aggregate Fluctuations: How Well Does the RBC Model Fit Postwar U.S. Data?", NBER Macroeconomics Annual 2004

[11] Haefke, C., Sonntag, M., Van Rens, T., 2013. "Wage Rigidity and Job Creation," Journal of Monetary Economics, 60(8), 887-899

[12] Hairault, J. O., Langot, F., Osotimehin, S., 2010. "Matching frictions, unemployment dynamics and the costs of business cycles," Review of Economic Dynamics 13, 759-779

[13] Hall, Robert E., 2005. "Employment Fluctuations with Equilibrium Wage Stickiness," American Economic Review, 95(1), 50-65

[14] Jung, P., Kuester K., 2011. "The (un)importance of unemployment fluctuations for the welfare cost of business cycles," Journal of Economic Dynamics \&5 Control 35, 1744-1768 
[15] Karabarbounis, L., Chodorow-Reich, G., 2014, "The Cyclicality of the Opportunity Cost of Employment," NBER Working Paper No. 19678

[16] Khan, A., King, R. G., Wolman, A. 2003. "Optimal Monetary Policy", Review of Economic Studies 70, 825-860.

[17] King, R. G., Wolman, A. 1999. "What Should the Monetary Authority Do When Prices Are Sticky?" NBER Macroeconomics Annual 1999, p. 349 404

[18] Krause, Michael U., Lubik., Thomas A., 2007. "The (Ir)relevance of Real Wage Rigidity in the NK Model with Search Frictions," Journal of Monetary Economics, 54(3), 706-727.

[19] Lubik, T.A., Schorfheide, F., 2004. "Testing for indeterminacy: an application to U.S. monetary policy," American Economic Review, 94, 190-217.

[20] Nakajima, T., 2010. "Optimal Monetary Policy with Imperfect Unemployment Insurance," Journal of Economic Dynamics and Control, 34, 365-387

[21] Petrongolo, B., Pissarides, C., 2001. "Looking into the black box: a survey of the matching function," Journal of Economic Literature, 39, 390-431.

[22] Petrosky-Nadeau N., Zhang L., July 2013. "Unemployment Crises", NBER working paper 19207

[23] Pissarides, C., 2009. "The Unemployment Volatility Puzzle: Is Wage Stickiness the Answer?", Econometrica, 77(5), 1339-1369

[24] Pizzo, A., 2014. "The Shimer Puzzle(s) in a New Keynesian Framework," PSE Working Paper

[25] Ravenna, F., Walsh, C. E., 2011. "Unemployment, sticky prices, and monetary policy: A linear-quadratic approach," American Economic Journal: Macroeconomics, 3(2), 130 - 162

[26] Ravenna, F., Walsh, C. E., 2012. "Monetary Policy and Labor Market Frictions: a Tax Interpretation", Journal of Monetary Economics 59, 180195

[27] Schmitt-Grohé, S., Uribe, M., 2004. "Solving Dynamic General Equilibrium Models Using a Second-Order Approximation to the Policy Function," Journal of Economic Dynamics \& Control, 28, 755-775

[28] Schmitt-Grohé, S., Uribe, M., 2006. "Optimal Fiscal and Monetary Policy in a Medium-Scale Macroeconomic Model," in Gertler, Mark and Kenneth Rogoff, eds., NBER Macroeconomics Annual 2005, MIT Press: Cambridge MA, 2006, 383-425.

[29] Shimer, R., 2005. "The Cyclical Behavior of Equilibrium Unemployment and Vacancies," American Economic Review, 95(1), 25-49. 
[30] Silva, J., Toledo, M., 2006. "Labor Turnover Costs and the Behavior of Vacancies and Unemployment," Working Paper

[31] Thomas, C., 2008. "Search and matching frictions and optimal monetary policy," Journal of Monetary Economics, 55(5), 936-956.

[32] Walsh, C., 2014. "Multiple Objectives and Central Bank Trade-Offs Under Flexible Inflation Targeting," Keynote address, 16th Annual Inflation Targeting Seminar, Banco Central do Brazil, May 15-16 2014 


\section{Appendix}

\subsection{Proof of the proposition of section 3}

Consider the employment flow equation

$$
N_{t}=(1-\rho) N_{t-1}+p_{t}\left[1-(1-\rho) N_{t-1}\right]
$$

and unemployment is $u_{t}=1-N_{t}$. The terms in brackets can be rewritten $\rho+(1-\rho) u_{t-1}$. Assuming all variables are covariance stationary, we have that

$$
\rho E\left(N_{t}\right)=\rho E\left(p_{t}\right)+(1-\rho)\left[\operatorname{cov}\left(p_{t}, u_{t-1}\right)+E\left(u_{t}\right) E\left(p_{t}\right)\right]
$$

In steady state $\rho N=\rho p+(1-\rho) u p$. We can rewrite

$\rho\left[E\left(N_{t}\right)-N\right]=\rho\left[E\left(p_{t}\right)-p\right]+(1-\rho) \operatorname{cov}\left(p_{t}, u_{t-1}\right)+(1-\rho)\left[E\left(p_{t}\right)-p\right] E\left(u_{t}\right)+(1-\rho)\left[E\left(u_{t}\right)-u\right] p$

We have that $E\left(N_{t}\right)-N=-\left(E\left(u_{t}\right)-u\right)$. Thus

$$
E\left(u_{t}\right)-u=-\frac{1-\rho}{\rho+(1-\rho) p}\left[\operatorname{cov}\left(p_{t}, u_{t-1}\right)+\left(\frac{\rho}{1-\rho}+E\left(u_{t}\right)\right)\left(E\left(p_{t}\right)-p\right)\right]
$$

\subsection{First-order conditions of the Ramsey problem}

The first order conditions obtained by solving the Ramsey problem detailed in section 5.1 are

$$
\begin{gathered}
m c_{t}: \lambda_{3 t} Z_{t}+\lambda_{4 t} \varepsilon=0 \\
\Pi_{t}:-\lambda_{1 t} \phi^{p}\left(\Pi_{t}-1\right) Z_{t} N_{t}+\phi^{p}\left(2 \Pi_{t}-1\right) C_{t}^{-\sigma}\left(\lambda_{4 t-1} \frac{Z_{t} N_{t}}{Z_{t-1} N_{t-1}}-\lambda_{4 t}\right)=0 \\
\theta_{t}:-\lambda_{1 t} \kappa\left(1-(1-\rho) N_{t-1}\right)+\lambda_{2 t} \mu(1-\alpha)\left(1-(1-\rho) N_{t-1}\right) \theta_{t}^{-\alpha}+\frac{\kappa}{\mu} \alpha \theta_{t}^{\alpha-1} C_{t}^{-\sigma}\left((1-\rho) \lambda_{3 t-1}-\lambda_{3 t}\right)=0 \\
N_{t}: \lambda_{1 t}\left[Z_{t}\left(1-\frac{\phi^{p}}{2}\left(\Pi_{t}-1\right)^{2}\right)-b\right]-\lambda_{2 t}+\beta \lambda_{2 t+1}(1-\rho)\left(1-\mu \theta_{t+1}^{1-\alpha}\right)+\beta \lambda_{1 t+1}(1-\rho) \kappa \theta_{t+1} \\
-\lambda_{4 t} \beta C_{t+1}^{-\sigma} \phi^{p} \Pi_{t+1}\left(\Pi_{t+1}-1\right) \frac{Z_{t+1} N_{t+1}+\lambda_{4 t-1} C_{t}^{-\sigma} \phi^{p} \Pi_{t}\left(\Pi_{t}-1\right) \frac{Z_{t}}{Z_{t-1} N_{t-1}}=0}{C_{t}: C_{t}^{-\sigma}-\lambda_{1 t}+\lambda_{3 t} \sigma C_{t}^{-\sigma-1}\left(Z_{t} m c_{t}-\omega Z_{t}^{\gamma}-\frac{\kappa}{\mu} \theta_{t}^{\alpha}\right)-\lambda_{4 t} \sigma C_{t}^{-\sigma-1}\left[1-\varepsilon+\varepsilon m c_{t}-\phi^{p} \Pi_{t}\left(\Pi_{t}-1\right)\right]} \\
-\lambda_{3 t-1} \sigma C_{t}^{-\sigma-1}(1-\rho) \frac{\kappa}{\mu} \theta_{t}^{\alpha}-\lambda_{4 t-1} \sigma C_{t}^{-\sigma-1} \phi^{p} \Pi_{t}\left(\Pi_{t}-1\right) \frac{Z_{t} N_{t}}{Z_{t-1} N_{t-1}}=0
\end{gathered}
$$


In steady-state, the first-order condition with respect to inflation is given by $-\lambda_{1} \phi^{p}(\Pi-1) Z N=0$. The resource constraint is binding in equilibrium so we have that $\lambda_{1} \neq 0$. Since $\phi^{p}>0$, it follows that $\Pi=1$. The optimal steady-state level of inflation is equal to zero.

\subsection{Conditional welfare according to the response to in- flation and employment}

8.3.1 $b=0$

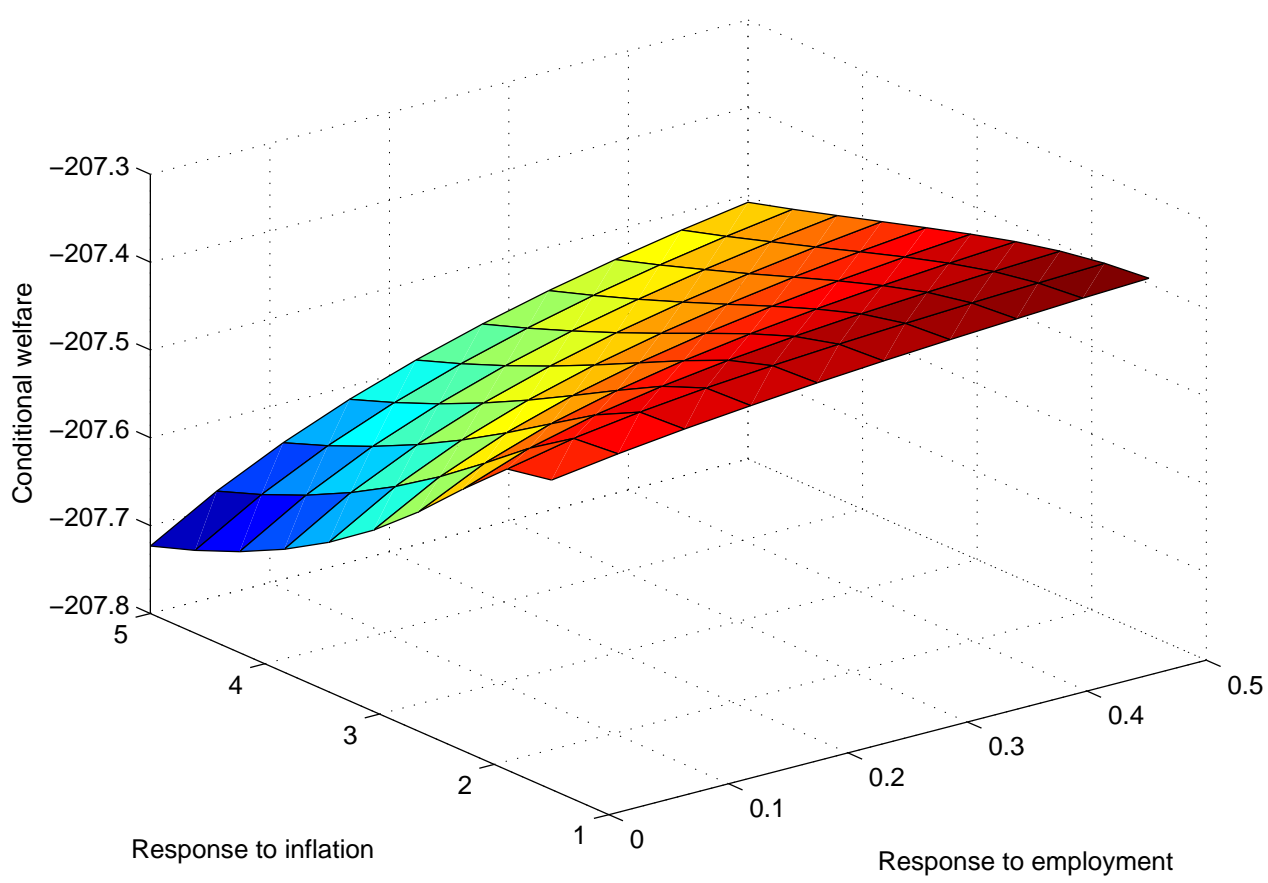

Figure 6: Conditional welfare according to the response to inflation and employment when $b=0$ 
8.3.2 $\quad b=0.4$

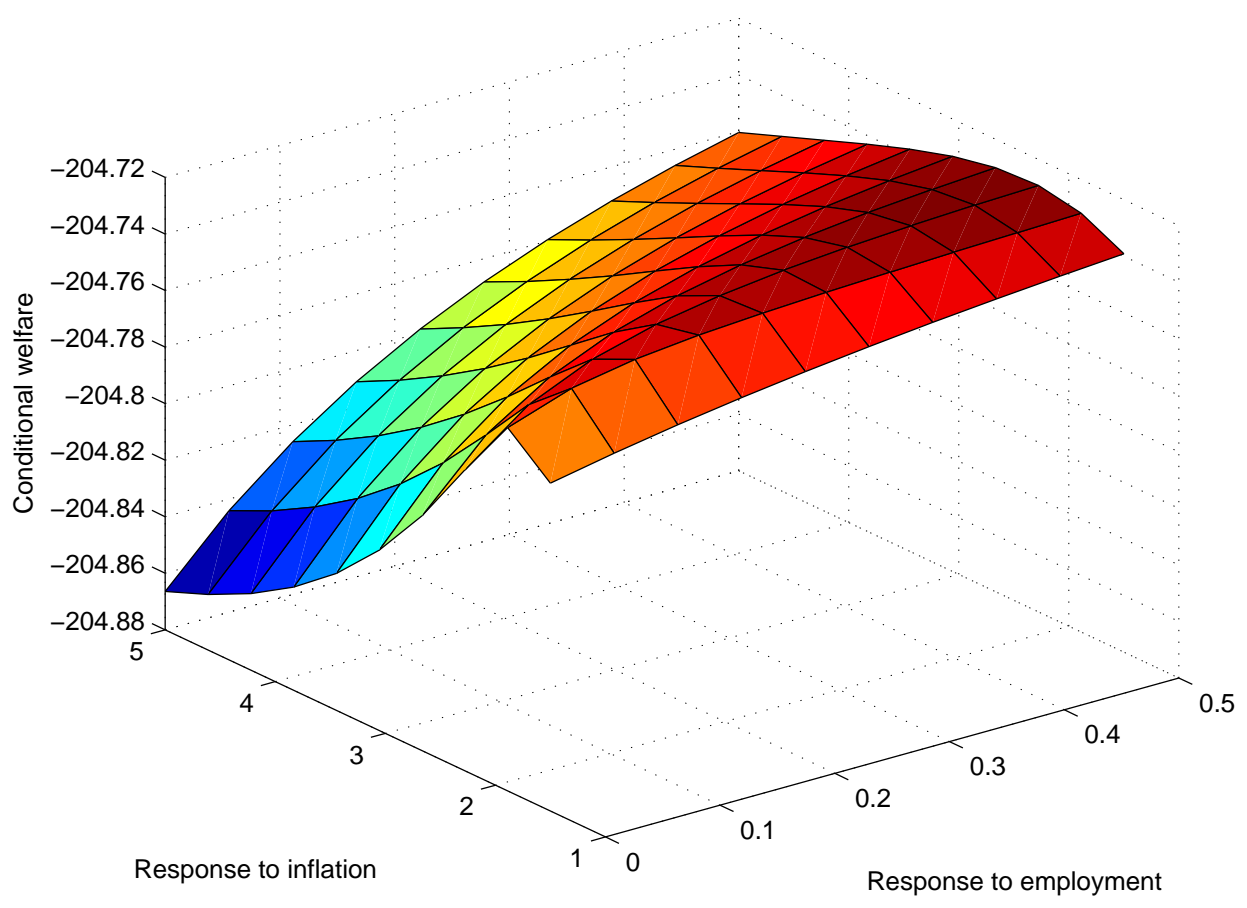

Figure 7: Conditional welfare according to the response to inflation and employment when $b=0.4$ 


\subsection{3 $b=0.7$}

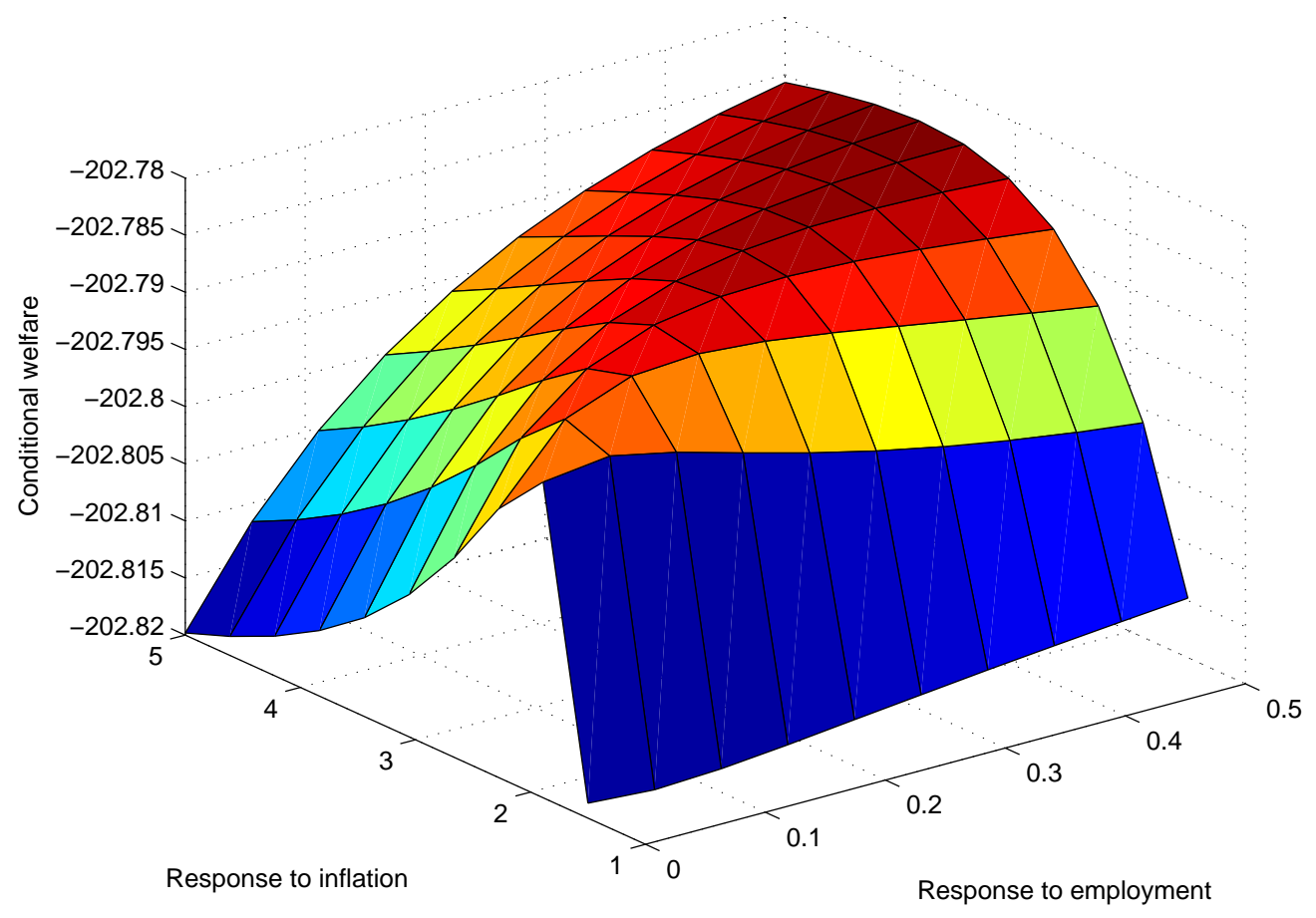

Figure 8: Conditional welfare according to the response to inflation and employment when $b=0.7$ 